\title{
On the Efficiency of the New York Independent System Operator Market for Transmission Congestion Contracts
}

\author{
Afzal S. Siddiqui, Emily S. Bartholomew, Chris Marnay, \\ and Shmuel S. Oren*
}

31 March 2003

\footnotetext{
* Siddiqui: Visiting Post-doctoral Researcher, Electricity Market Studies, Environmental Energy Technologies Division, Ernest Orlando Lawrence Berkeley National Laboratory, Berkeley, CA 947208061, USA.e-mail: ASSiddiqui@lbl.gov.

Bartholomew: Senior Research Associate, Electricity Market Studies, Environmental Energy Technologies Division, Ernest Orlando Lawrence Berkeley National Laboratory, Berkeley, CA 94720-8061, USA. email: ESBartholomew@lbl.gov.

Marnay: Staff Scientist, Electricity Market Studies, Environmental Energy Technologies Division, Ernest Orlando Lawrence Berkeley National Laboratory, Berkeley, CA 94720-8061, USA. e-mail: C_Marnay@lbl.gov.

Oren: Professor, Department of Industrial Engineering and Operations Research, University of California, Berkeley, CA 94720, USA. e-mail: oren@ieor.berkeley.edu.

The authors would like to thank the following colleagues at Berkeley Lab for valuable feedback: Bernie Lesieutre, Chuck Goldman, Joe Eto, and Jenny Edwards. Also providing helpful comments were Jussi Keppo of the University of Michigan at Ann Arbor, Chris Knittel of the University of California at Davis, Andrew Lim of the University of California at Berkeley, Shijie Deng of the Georgia Institute of Technology, Jim Bushnell and Celeste Saravia of the University of California Energy Institute, Tim Mount and Bob Thomas of Cornell University, Camden Collins of Bearing Point, and Scott Harvey of LECG. Much of the empirical analysis would not have been possible without the assistance of the employees of the New York Independent System Operator, Jack Valentine, Art Desell, and Dave Lawrence. Most data used in this paper are available on line at electricitymarketdata.lbl.gov.
} 


\section{Abstract}

The physical nature of electricity generation and delivery creates special problems for the design of efficient markets, notably the need to manage delivery in real time and the volatile congestion and associated costs that result. Proposals for the operation of the deregulated electricity industry tend towards one of two paradigms: centralized and decentralized. Transmission congestion management can be implemented in the more centralized point-to-point approach, as in New York state, where derivative transmission congestion contracts (TCCs) are traded, or in the more decentralized flowgate-based approach. While it is widely accepted that theoretically TCCs have attractive properties as hedging instruments against congestion cost uncertainty, whether efficient markets for them can be established in practice has been questioned. Based on an empirical analysis of publicly available data from years 2000 and 2001, it appears that New York TCCs provided market participants with a potentially effective hedge against volatile congestion rents. However, the prices paid for TCCs systematically diverged from the resulting congestion rents for distant locations and at high prices. The price paid for the hedge not being in line with the congestion rents, i.e. unreasonably high risk premiums are being paid, suggests an inefficient market. The low liquidity of TCC markets and the deviation of TCC feasibility requirements from actual energy flows are possible explanations.

\section{Introduction}

Typically, infrastructure industries, e.g., those involving energy, telecommunications, and transportation, have been subject to government regulation due to their natural monopoly characteristics. ${ }^{1} \quad$ Thus, regulation removes the need for multiple firms or duplicate transportation networks within a geographic region. Indeed, it might be economically inefficient to build several parallel roads between any two destinations when one road conveys traffic just as effectively, despite the potential benefits of competition.

Among infrastructure industries, electricity especially required government regulation due to its lack of storability, the complex nature of its transmission (i.e., delivery from generator to consumer), and to a lesser extent, economies of scale in its generation. In particular, electricity transmission, unlike other transportation networks, requires coördinated behavior to ensure that injections and withdrawals of electricity are continuously balanced. ${ }^{2}$ This coördination is necessitated by physical laws that distribute electricity among all possible paths between generator and load in quantities relative to path impedances. Electrical energy cannot be directed from specific generator to specific consumer, and events occurring at one network node have implications for the entire system. Therefore, any fully decentralized system would prove impracticably complex

\footnotetext{
${ }^{1}$ These imply that costs decline with output and that a single extensive network is sufficient to deliver the final product to consumers.

${ }^{2}$ Since electricity cannot be economically stored on a large scale, smoothing deliveries by inventories is impossible.
} 
because it would have to be balanced in real-time to prevent its collapse. As a result, electricity supply functions, such as generation and transmission, were historically kept vertically integrated under a single regulated entity that exclusively provided all services related to electricity supply within a given geographic region.

While vertical integration of generation and transmission internalized many operating and investment complementarities, viz., the coördination of efficient electricity dispatch, it, nevertheless, turned the potentially competitive generation sector into a de facto monopoly. In order to provide incentives for efficient operation, the electricity industry has been restructured in many jurisdictions. In general, this has meant unbundling of the various electricity services so that the layers suitable for competitive supply may be provided by specialized firms subject to light regulation. As identified in Joskow (1997), the four main electricity supply functions provided by an investor-owned utility (IOU) are:

- generation: conversion of primary energy to electricity.

- transmission: transportation of electricity along the meshed high-voltage grid to substations.

- distribution: transportation of electricity along radial low-voltage wires from substation to customer meters.

- retailing: arrangements for billing, on-site support, and demand management.

In general, the generation and retailing sectors have seen the promotion of competition because economies of scale are either exhausted at current levels of production or are not applicable at all there (see Wolak (2000)). These services can, thus, to be provided through competitive markets. For the incumbent utilities, this has generally implied either divestiture of their generation assets or their segregation in unregulated parts of the company. The transmission and distribution sectors, however, continue to be regulated because of their natural monopoly characteristics. Outside of these broad guidelines, the actual paths taken by electricity industry restructuring movements vary considerably across jurisdictions.

The contours of these reforms, as traced out in Wilson (2002), touch upon the two extremes in electricity market design. One approach is highly centralized in that it seeks to emulate the tight control of the vertically integrated paradigm by exploiting the complementarities between generation and transmission. In this environment, an independent system operator (ISO) not only manages the transmission system, but also conducts a de facto market by centralized dispatch. Such a framework works best when ample competition and accurate information is available for the ISO's optimization problem. ${ }^{3}$ At the other extreme is a decentralized approach in which an official market is not even required. Instead of there being a centralized dispatch, market agents can transact bilaterally or through markets, such as a day-ahead power exchange (PX), with the ISO charged only with protecting system reliability and correcting real-time energy

\footnotetext{
${ }^{3}$ These systems are typically outgrowths of preëxisting centrally coördinated power pools or nationally dispatched electricity sectors.
} 
imbalances. ${ }^{4}$ Since there is no explicit coördination of electricity, reserves, or transmission markets, such an environment requires a profusion of trading opportunities in order to allocate resources efficiently.

In addition to generating electrical energy, an electricity supplier must have the means to deliver this energy to the point of enduse at the instant of consumption. Deliveries cannot be levelized by inventories. Therefore, well-defined transmission rights are crucial to efficient electricity production. Rights can be physical or financial but, at least in the U.S., restructuring efforts to date have favored financial. These rights function not only as hedging instruments, but also as mechanisms for prioritizing scheduling, that is, ensuring the most profitable electricity trades take place. Additionally, the congestion rents collected from market participants dispatching electricity over congested links should provide price signals to guide future investment in the transmission infrastructure, although whether these signals can be turned into effective incentives has been hotly debated (see Bushnell and Stoft (1997)). Further, efficient congestion management can remove market fragmentation, thereby mitigating the exercise of market power. At the same time, however, any set of transmission rights must promote coördinated behavior in order to internalize the effects of Kirchhoff's Laws which govern the movement of energy on the grid. These Laws result in power flowing not according to the shortest or contract path but according to the physical nature of the transmission lines. Flows along multiple paths from the generator to consumer of energy are called loop flows and will affect other transactions. Not only is there not a unique route between generator and load, but also more importantly that energy consumed by customers comes from sources quite different from the power plant with which the consumer has contracted. Stoft offers a good introduction to the complexities these physical realities imply (see Stoft (2002)). Similar to the general debate over the nature of electricity industry restructuring, the specific discussion concerning congestion management within a deregulated framework can also be roughly categorized into those advocating centralized and decentralized paradigms (see Bushnell (1997)).

Prior to restructuring, a contract path approach to transmission scheduling was common. This method calculates the transfer capacity of the links between any two points on the network using power transfer distribution factors (PTDFs), based on the myth that energy would flow along a known path from generator to consumer. ${ }^{5}$ The ownership of these transmission rights confers a physical right to transmission capability. In order to keep generator dispatch feasible and to account for loop flows caused by Kirchhoff's Laws, in principle point-to-point (PTP) rights must be determined for both each pair of points in the network and each set of network conditions. Moreover, because of the number of rights issued for a given path depends on those issued for other paths, externalities abound; that is, consummated transactions affect other transactions between quite different parties. Advocates of centralized restructured paradigms for the power sector

\footnotetext{
${ }^{4}$ Implicit in this definition is that the ISO ensures the feasibility of executed trades given the grid's transfer capabilities.

${ }^{5}$ Each PTDF represents the constant fraction of the capacity of each link along the contract path that is required. As discussed previously, however, there is no unique relationship between the generator and the point of consumption. Due to Kirchhoff's Laws, the energy consumed is very likely being generated at a plant that is different from the contracted one.
} 
favor locational pricing systems with a PTP approach to congestion management because it offers a centralized framework within which to provide adequate congestion cost hedging opportunities (see Hogan (1992) and Harvey et al. (1996)). Typically, in this approach, financial, rather than physical, rights to congestion revenues are proposed. This approach also serves to guarantee prices to consumers, potentially eliminating the considerable variability in congestion costs.

Proponents of a more decentralized paradigm, however, argue that the PTP approach obfuscates congestion risk management by market participants, and does not provide effective hedging instruments. Their arguments, while accepting the desirable theoretical properties of PTP rights, focus on the low likelihood these markets can operate efficiently in practice. This results in price distortions and inefficient dispatch even if generation is competitive (see Oren (1997a) and Oren (1997b)). As an alternative to the PTP approach, decentralized congestion management might establish trading of rights only along congested transmission bottlenecks (or, flowgates). In contrast to the PTP approach, flowgate-based systems have transmission congestion rights that depend on the network topology and are fixed by the physical capabilities of the grid (see Chao and Peck (1996), Chao and Peck (1997), and Chao and Peck (1998)). Because PTDFs remain relatively constant over time, the number of flowgate rights is also stable, thereby improving market liquidity and enabling more transparent congestion risk management (see Chao et al. (2000)). Congestion along the full length of a contract path can be hedged by holding a portfolio of flowgate rights. Also, the responsibility for congestion cost risk falls to the parties in an energy sale transaction, i.e., rights trading becomes more firmly linked to the energy market. Advocates of flowgate rights argue more efficient congestion markets will in turn enable more efficient energy markets, which is the key objective. Consequently, they tend to talk of these rights as active rather than the passive financial rights (see Oren (1997b)). More recently, analysts have also turned their attention to possible relationships between the organization of congestion markets and market power opportunities (Stoft (1999) and Joskow and Tirole (2000)).

While the literature described provides an ongoing rich debate on the relative theoretical properties of congestion rights schemes, to date relatively little empirical work has been done on actual functioning congestion rights markets. In this paper, we analyze the effectiveness of transmission congestion risk management in New York, which employs a PTP passive financial congestion rights approach, i.e., a system similar to the one proposed in Hogan (1992) and Harvey et al. (1996). We begin in Section 2 by describing the deregulated New York framework, its markets for transmission congestion management, a theoretical overview of risk hedging using forward contracts, and a discussion of the complexity of PTP congestion revenue rights. Next, in Section 3, we discuss the empirical methodology employed. In Section 4, we present our results and interpret them in terms of the debate concerning the design of markets for transmission congestion management. Finally, in Section 5, we offer concluding remarks and directions for future research. 


\section{Transmission Management in New York}

\subsection{NYISO Control Area Structure}

The New York Independent Systems Operator (NYISO) is a not-for-profit organization charged with reliably operating the electric grid and running fair and open wholesale electricity markets in the New York Control Area (NYCA), which consists of the entire state of New York. All electricity that passes through its grid must be scheduled through the NYISO. Approximately half of this electricity is purchased through either the dayahead or real-time wholesale electricity markets operated by the NYISO. The other half is traded on bilateral contracts.

The state is divided into eleven load zones, shown in Figure 1. The clearing price of the market at any point on the NYCA system, or the Locational Based Marginal Price (LBMP), is based on the cost of providing the next MW increment of load to the system. The LBMP is calculated by the NYISO for each load zone and at each of over 400 specific generation buses, or points of injection (POI). Buyers pay the LBMP calculated for the congestion zone in which they take delivery of electricity, or the point of withdrawal (POW), and sellers receive the LBMP at the bus to which they supply. When all electricity can be supplied at lowest cost, the price is almost uniform across the state, varying only because of losses in the grid. Even when this ideal outcome is prevented by congestion, the price of the minimum cost dispatch, known as the LBMP at the reference bus, is the benchmark for all actual prices. Often, different locations have different market-clearing prices because of congestion. Buyers that purchase electricity at a point ultimately pay the congestion rent, which is included in the LBMP; however, sellers and traders establishing fixed contract prices for delivered electricity are exposed to congestion rent uncertainty. Because congestion rents can be volatile and unpredictable, risk-averse market participants want to hedge against this exposure. 


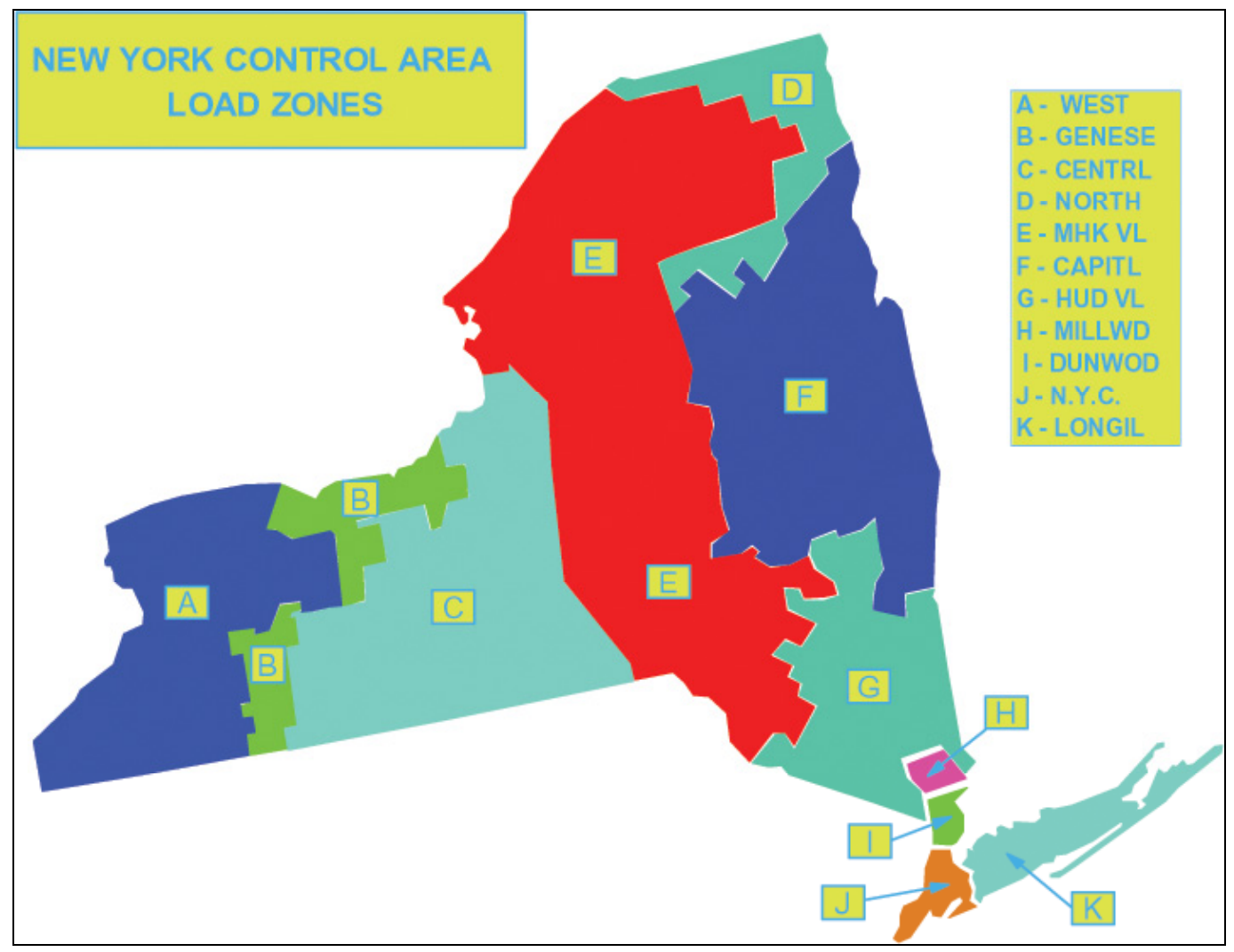

Figure 1. NYISO Congestion Zones

\subsection{NYISO TCC Markets}

The NYISO created the transmission congestion contract (TCC) market as a way for market participants to hedge against volatile congestion rents (see p. 36, item $1.44 \mathrm{e}$ in NYISO (2000)). TCCs can be defined between the eleven congestion zones, the four neighboring control areas (Ontario, PJM, New England, and Québec), and the hundreds of buses for which the NYISO calculates LBMP. In all, there are approximately 120,000 permutations of POIs and POWs.

TCCs entitle the holder to collect the congestion rent between two points (zone, substation, or generation bus) on the NYCA system for every hour during a given time interval, or effective period. Currently TCCs can be purchased from either of two NYISO auctions, initial and reconfiguration. Buyers in either auction are known as primary holders. TCCs can also be freely disaggregated and traded in the secondary market. A summary of the auctions is included below (see Table 1). Initial auctions, which take place twice a year, consist of two stages with a variable number of rounds in each stage. Each set of rounds trades TCCs with only one effective period. For example, a single set of rounds exists for two-year TCCs. One-Year TCCs are then sold in subsequent rounds. Thus far the TCCs have had effective periods consisting of all hours for six months, one year, two years or five years, although this may change in the future. Stage 1 consists of at least four rounds, unless otherwise decided by transmission owners. The percentage of 
available transmission system capability awarded in each round of Stage 1 as TCCs is determined by the NYISO. Primary holders of TCCs may offer their TCCs for resale in either stage; participants who were awarded TCCs in Stage 1 can offer those TCCs for resale in Stage 2. The initial auction is expected to eventually be replaced by an end-state auction, in which auction participants will determine the effective period for each TCC awarded (see Attachment M, sections 2.0 and 8.4 of NYISO (2000)). A summary of exact auction stages, rounds, and dates appears in Table 18.

Table 1. NYISO TCC Auction Summary

\begin{tabular}{|c|c|}
\hline $\begin{array}{l}\text { Initial Auction } \\
\text { (NYISO organized) }\end{array}$ & $\begin{array}{l}\text { - Held twice a year } \\
\text { - ISO determines effective period (six months, one year, two } \\
\text { years, five years) for TCCs and percentage of transmission } \\
\text { system capability available for the purchase of TCCs } \\
\text { auctioned in each round } \\
\text { - Consists of two multi-round stages } \\
\text {-Stage 1: at least four rounds, unless otherwise decided by } \\
\text { transmission owners } \\
\text {-Stage 2: (reconfiguration stage) varying number of rounds } \\
\text { - Market-clearing price set for each round any POI/POW } \\
\text { pairs traded } \\
\text { - TCCs valid for every hour of the effective period } \\
\text { Will be replaced by End-State Auction }\end{array}$ \\
\hline $\begin{array}{l}\text { Reconfiguration } \\
\text { Auction } \\
\text { (NYISO organized) }\end{array}$ & $\begin{array}{l}\text { - Held monthly } \\
\text { - Allows holders of TCCs to sell for every hour of the } \\
\text { following month only }\end{array}$ \\
\hline Secondary Market & $\begin{array}{l}\text { - } \quad \text { Terms determined bilaterally by the trading partners } \\
\text { - } \quad \text { NYISO deals only with primary holder }\end{array}$ \\
\hline $\begin{array}{l}\text { End-State Auction } \\
\text { (NYISO organized) }\end{array}$ & $\begin{array}{l}\text { - Not active yet } \\
\text { - Bidders will determine effective period for TCCs } \\
\text { (otherwise, similar to Initial Auction) }\end{array}$ \\
\hline
\end{tabular}

Monthly reconfiguration auctions allow primary holders to sell TCCs for all hours of the following month. Primary holders of TCCs may also sell those TCCs in the secondary market to secondary holders, i.e., market participants who do not purchase TCCs in an auction. Secondary market bilateral trades can be on any terms to which the two parties agree. For example, a secondary trade could be for specific days of the month or hours of a day. Other than the initial choice of effective periods and the reconfiguration auctions, the secondary market is currently the only way for sellers and buyers to tailor the TCCs. The secondary market is not regulated by the NYISO, and all settlements are made with the primary holder, the party that purchased the TCC in a NYISO auction. If secondary holders wish to deal directly with the NYISO, they may apply to become primary holders with the NYISO if they meet the relevant financial requirements of the NYISO. 
A key implementation issue should also be mentioned here. The introduction of competition into electricity markets of course changes the value of historic properties and contracts, including transmission rights. TCCs offer ideal instruments for converting historical entitlements to firm transmission capacity into tradable entitlements that keep the holders of such entitlements just as well-off economically while enabling them to cash out when others can make more efficient use of the transmission capacity covered by these entitlements. In other words, TCCs make it relatively easy to maintain the profits of the historical entitlement holders while opening up the transmission system to more efficient use, which should satisfy a key constituency in restructuring proceedings.

Before the first NYISO TCC auction, all parties with existing transmission agreements were assigned grandfathered rights, which could be converted to TCCs identical to TCCs purchased in auctions, except that the effective period is the length of the original right. These TCCs can be bought and sold equivalently with new TCCs. Therefore, the holders of historic rights can either continue to perform on their existing agreement and are perfectly hedged against any congestion rent at no cost. Alternatively, if the established price of TCCs provides a more attractive option, or the contract ends prematurely, the TCC can be sold, and access to the grid passes to higher value transactions. One of the most attractive public policy features of TCCs is that they offer this convenient path to competitive open transmission access, which as argued above, is critical to establishing a competitive electricity market. Moreover, as with the other desirable aspects of financial transmission rights, capturing these benefits requires that an efficient market be quickly established. If it is not, neither are the holders of grandfathered rights properly compensated, nor does access to the grid pass to the highest value users. However, since holders of grandfathered rights are given TCCs tailored to the terms of their transaction, they are fully hedged against congestion rents while they hold their TCCs. In many ways, this problem resembles the allocation of historic pollution rights and similar market problems could ensue (see, for example, Kolstad (2000)). Once grandfathered rights and TCCs were determined, the remaining transmission capability was allocated to transmission owners, who were then obligated to offer this capacity for sale in the auction.

In both initial and reconfiguration auctions, each TCC bid consists of a POI, a POW, the capacity in MWs, and a price per MW. There is a single clearing price for each permutation of POI and POW in each round. Nodal prices, which allow the clearing price for any POI/POW pair to be calculated, are published on the NYISO website (http://www.nyiso.com/oasis) between rounds of the auction.

The holder of a TCC is entitled to the LBMP-based congestion rent between the POI $I$ and the POW $W$ for all hours in the effective time interval (of length $T$ ) of the contract. This congestion rent for hour $t$ by market participant $j, R_{I, W}^{t, j}$, is calculated as the congestion component of the LBMP at the POW $\left(p_{W}^{t}\right)$ minus the congestion component of the LBMP at the POI $\left(p_{I}^{t}\right)$ multiplied by the number of MWs owned during the time interval of length $T$ by market participant $j, N_{I, W}^{T, j}$ : 


$$
R_{I, W}^{t, j}=\left(p_{W}^{t}-p_{I}^{t}\right) \cdot N_{I, W}^{T, j} \forall t=1, \ldots, T \text { and } \forall j=1, \ldots, J
$$

\section{Equation 1}

Because these contracts are unidirectional, the holder is also responsible for paying congestion rent which accrues in the opposite direction (i.e., when $R_{I, W}^{t}$ is negative). A TCC can exist between any two allowable points in the NYCA system.

The clearing price of a TCC determined through a NYISO auction can be negative, which means the NYISO will pay the buyer the clearing price for accepting it. This would occur if a buyer predicts congestion in the opposite direction to that for which the TCC is defined. For example, a TCC defined between a POI in New York City and a POW in the western part of the state could evoke a negative clearing price if the buyers and sellers in the auction quite reasonably predict that congestion will occur into New York City. Alternatively, a positive price paid for a TCC suggests that the buyer expects to collect positive rent. The data-reporting convention of the NYISO, takes its own point of view. Congestion rents collected by the TCC holder are reported as negative values, i.e. money is leaving the ISO, while positive values signify reverse congestion rent the holder is responsible for paying, i.e., money is entering the ISO. Therefore, a stream of negative rents reported in NYISO data means the holder of a TCC is collecting rents. To illustrate, a buyer contracting to buy and transmit power into New York City (zone J, N.Y.C. in Figure 1), to which access has historically been congested about $50 \%$ of the time, will typically pay a positive price for a TCC going into the zone $\mathrm{J}$, and receive the positive rents paid by users of that transfer capacity, but the later will be reported as negatives by the NYISO.

\subsection{Theory of Risk Hedging}

In order for TCCs to be effective hedges against congestion charges, their procurement cost must accurately reflect the cumulative congestion rents to be collected over the contracted effective period. For example, the amount paid to secure a six-month TCC from a POI to a POW, should at least be correlated with the cumulative hourly congestion rent between these two points during this time interval. For TCCs to be perfect hedges, in the long-run, ignoring interest rates, the TCC procurement cost per MW for a time interval of length $T$ between a POI $I$ and a POW $W, c_{I, W}^{T}$, should be an unbiased estimator of the average congestion rent, $R_{I, W}^{T}=\frac{\sum_{j=1}^{J} \sum_{t=1}^{T} R_{I, W}^{t, j}}{\sum_{j=1}^{J} N_{I, W}^{T, j}}$, where $t$ is a time period index. In other words, a necessary condition for TCCs to be perfect hedges is

$c_{I, W}^{T}=E\left[R_{I, W}^{T}\right]$. For example, this would mean that an electricity seller could exactly hedge against the congestion rent between a POI/POW pair. If actual congestion rents are greater (less) than the seller's expectation, then it breaks even by recovering greater (lesser) financial congestion rents from its TCC transaction than the purchase implied. More generally, TCCs can still be effective hedges by reducing the variance of the cash 
flow resulting from uncertain transmission congestion as long as their procurement costs are correlated with the congestion rents. A market participant simply has to purchase enough of the TCC to hedge its transmission congestion exposure perfectly. The longrun consequence of this set of transactions is that the TCC price equilibrates to the expected cumulative congestion rent by the principle of arbitrage. ${ }^{6}$

A complete treatment of hedging would compare the TCC price paid and the actual physical congestion rent incurred by the market participant. Since determining the latter quantity is not possible with the publicly available data, we merely describe here the approach that could be taken. We assume that for a given POI/POW pair, a market participant has to pay an uncertain congestion rent $S_{t}(\omega)=N p_{t}(\omega)$ at time $t$, where $N$ is the number of MWs required, $p_{t}(\omega)$ is the per MW (uncertain) congestion component of the spot price at time $t$, and the random variable $\omega$ denotes that the price is uncertain at the time that the TCC is procured. Suppose this risky transaction can be hedged by purchasing at time 0 a quantity $C_{t}$ of a forward instrument, such as the TCC, at its initial per MW price $f_{0}$. At time $t$, this contract is sold forward at price $f_{t}(\omega)$ per MW, which is unknown at time 0 . The resulting cash flow (or, wealth) in period $t$ is, thus, $W_{t}(\omega)=S_{t}(\omega)+\left(f_{0}-f_{t}(\omega)\right) C_{t}$. The riskiness of this cash flow is measured by its variance, i.e.,

$$
\operatorname{Var}\left(W_{t}(\omega)\right)=\operatorname{Var}\left(S_{t}(\omega)+\left(f_{0}-f_{t}(\omega)\right) C_{t}\right)=\operatorname{Var}\left(S_{t}(\omega)\right)+C_{t}{ }^{2} \operatorname{Var}\left(f_{t}(\omega)\right)-2 \operatorname{Cov}\left(S_{t}(\omega), f_{t}(\omega)\right) C_{t}
$$

\section{Equation 2}

Minimizing this with respect to $C_{t}$ yields

$$
C_{t}^{*}=\frac{\sigma_{p_{t}} \rho_{p_{t}, f_{t}}}{\sigma_{f_{t}}} N
$$

\section{Equation 3}

where $\sigma_{p_{t}}$ and $\sigma_{f_{t}}$ are the standard deviations of the spot and forward prices, respectively, and $\rho_{p_{t}, f_{t}}$ is the correlation coefficient between them (see Luenberger (1997)). The minimized variance of the cash flow is

$$
\left.\operatorname{Var}\left(W_{t}(\omega)\right)\right|_{C_{t}=C_{t} *}=\operatorname{Var}\left(S_{t}(\omega)\right)-\sigma_{p_{t}}^{2} \rho_{p_{t}, f_{t}}^{2} N^{2}
$$

\section{Equation 4}

It is worth noting that the quantity of forwards purchased, $C_{t}$, increases with the amount of MWs required, the degree of correlation between the forward and spot prices, and the volatility of the spot price. On the other hand, it decreases with the volatility of the forward price. Consequently, it is possible to reduce the variance of the cash flow if there is some (positive or negative) correlation between the forward and spot prices. In the extreme case where the forward commodity identically replicates the spot commodity, we

\footnotetext{
${ }^{6}$ Due to the complexities of market structure, arbitrage may not always be possible (see Section 2.4). Even if it were possible, it may not result in perfect equilibration of TCC prices and congestion rents because of risk aversion or illiquidity.
} 
have $\quad p_{t}(\omega)=f_{t}(\omega), \quad$ which implies $\quad E_{\omega}\left[p_{t}(\omega)\right]=E_{\omega}\left[f_{t}(\omega)\right], \quad \sigma_{p_{t}}=\sigma_{f_{t}}, \quad$ and $\operatorname{Cov}\left(p_{t}(\omega), f_{t}(\omega)\right)=\sigma_{p_{t}}^{2}=\sigma_{f_{t}}^{2}$. Therefore, $\rho_{p_{t}, f_{t}}=1$, and $C_{t}{ }^{*}=N$, which implies that $\left.\operatorname{Var}\left(W_{t}(\omega)\right)\right|_{C_{t}=C_{t^{*}}}=0$. Hence, a perfect hedge is possible if the forward commodity behaves exactly as the spot commodity. TCCs offer the promise of providing an excellent hedge because there is a direct relationship between the congestion rent a buyer must pay on an electricity purchase and the revenue on a TCC. This benefit can only be captured, however, if TCCs are properly priced in efficient markets.

A low level of correlation between the TCC price and the congestion rent (the forward and the spot commodities, respectively), however, implies that the level of risk associated with hedging increases, thereby making the hedge less effective. While any level of correlation between the spot and forward diminishes cash flow volatility, if either the correlation coefficient approaches zero or the variance of the forward price relative to the spot price increases without bound, then the market participant is better off using some other instrument to hedge its spot market transactions. Indeed, in such a scenario, the existing forward contract, i.e., the TCC, is no longer an effective hedge and is simply a lottery.

Since the actual physical congestion rent exposure of each market participant is not known, the subsequent analysis focuses instead on the relationship between the price paid for TCCs and the resulting congestion rent received, which is an indicator of market efficiency. This determines empirically whether the prices paid for TCCs at least reflected the returns. Note that we abstract from considering cycles in the underlying demand for electricity as done in Audet et al. (2002). As a result, we implicitly assume that the correlation and volatility remain constant over time. A complete treatment of risk hedging would consider this issue in more detail.

\subsection{Complexities of PTP Congestion Revenue Rights}

In evaluating financial hedging instruments and market performance two questions must be addressed:

1. How good is the hedge, i.e., to what extent does the revenue stream offset the fluctuations in the risky cash flow that the instrument is supposed to hedge?

2. How efficient is the market, i.e., does the market price of the forward instrument reflect the expected risky cash flow hedged by the instrument with the proper risk premium adjustment?

Much of the discussion surrounding PTP congestion revenue rights, such as NYISO TCCs, focuses on the first question, and indeed TCCs potentially provide a perfect hedge against real-time congestion charges based on nodal prices. A $1 \mathrm{MW}$ bilateral transaction between two points in a transmission network is charged (or credited) the nodal price difference between the POW and the POI. At the same time, assuming that transmission rights are fully funded, a $1 \mathrm{MW}$ TCC between two points is an entitlement (or obligation) for the difference between the LBMPs at the POI and POW. Thus, regardless of how the 
system is dispatched, a 1 MW TCC between two nodes is a perfect hedge against the uncertain congestion charge between the same two nodes, as explained above.

New transmission users should view the TCC as a mechanism to hedge their exposure to congestion risk, while holders of granfathered rights should actively evaluate their commercial options with respect to their entitlements. Both should consider the second question above as relevant as the first. That is, a purchaser (or holder) of a TCC must assess whether the price of the forward instrument indeed reflects the value it provides in making the decision whether to purchase (or hold) the instrument or to face the exposure to the real time congestion charges.

In typical financial and commodity markets, competition and liquidity push forward prices to the expected spot prices with a proper (market-based) risk premium adjustment. Such convergence is achieved through a process of arbitrage. Arbitrage, however, may be more difficult when dealing with TCCs for several reasons:

1. Because of the large number of possible TCCs (about 120,000 are possible in the NYISO), liquidity of these instruments is relatively low, implying that there are few secondary markets that enable reconfiguration and reselling.

2. In order to maintain financial solvency of the system operator, who is the counter party to TCCs, the configuration of TCC types must satisfy the simultaneous feasibility conditions that are dictated by the physical system constraints. That is, the NYISO can only pay out congestion rents to TCC holds at approximately the same level it collects them. Consequently, pricing and trading of TCCs is done through a central periodic auction.

3. Because of the interaction among the different TCCs, through the simultaneous feasibility security-constrained power flow, prices of the TCC resulting from the auction, as well as the congestion charges hedged by these TCCs, are highly interrelated. An efficient market (i.e., one that correctly prices TCCs) must anticipate not only the uncertainty in congestion prices due to technical contingencies and load fluctuation, but also the shift in the operating point within the feasible region which is determined by the economic dispatch procedure.

To illustrate the potential obstacles to market efficiency we will consider an illustrative three-node example (see Figure 2). For simplicity we assume a direct-current (DC) model with no transmission losses and further assume that the transmission capacity on each line is fixed. Realistic considerations such as alternating-current (AC) networks, line losses, and $n-1$ contingency planning further impede the achievement of efficient TCC pricing.

In the following three-node network, all lines have equal reactance whereas their thermal limits (or flowgate constraints) are as shown. All the generators serve the load at node 3, and the two hedging instruments available are TCC 1-3 and TCC 2-3. The nomogram in Figure 3 illustrates the feasible region for all possible combinations of TCCs that will not violate any of the flowgate constraints. The facets of the nomogram represent these flowgate constraints. In the TCC auction, bids are submitted for the two TCC types, and the market is cleared in order to maximize total auction revenue. The market-clearing 
price for each of the TCCs is based on the respective marginal bids accepted. For instance, if bid prices for the two TCCs are about the same, then the TCC awards will be based on point $\mathrm{C}$ on the nomogram, and the TCC prices will equal the marginal bids corresponding to the awarded TCC quantities.

In real time, the optimal dispatch is determined so as to minimize total dispatch cost subject to thermal flow constraints and Kirchhoff's Laws. Depending on the energy offer prices of generators G1, G2, and G3 and the demand function of L3, the least-cost dayahead optimal dispatch ends up at point B on the nomogram. Both the day-ahead congestion prices and the TCC payouts are equal to the corresponding nodal price differences between nodes 2 and 3 and 1 and 3, respectively. These nodal prices are based on the day-ahead operating point B. Moreover, while the congestion charges are collected on the transactions reflected by point $\mathrm{B}$, the TCC quantities are based on the TCC award mix represented by point C. Since point $\mathrm{C}$ is a suboptimal day-ahead dispatch solution, it follows that the congestion charges will always suffice to cover the TCC settlement. However, the ratio of settlement prices (represented by the slope of the supporting line at point B) is different from the ratio of TCC prices represented by the slope of the supporting line at point $\mathrm{C}$. Therefore, in order for the market to price the TCCs correctly, it must account for uncertainty in load and generation prices as well as for the movements of the real-time operating point resulting from the dispatch optimization.

The empirical question addressed in this paper is whether, in spite of the perceived complexity, the market for TCC hedges is efficient in the sense that it can produce the correct TCC prices that are consistent with the risk they hedge against.

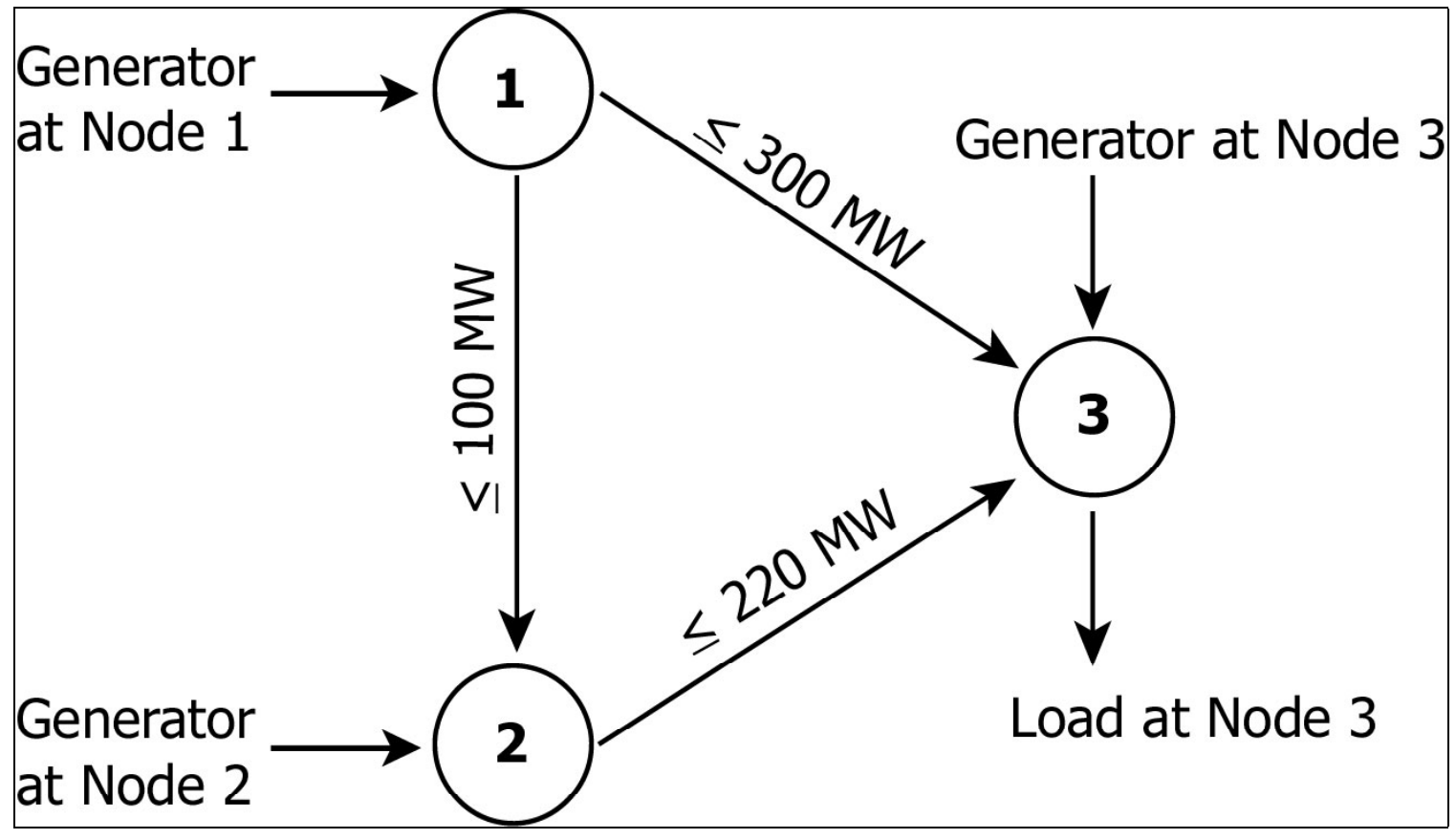

Figure 2. Three-Node DC Example 


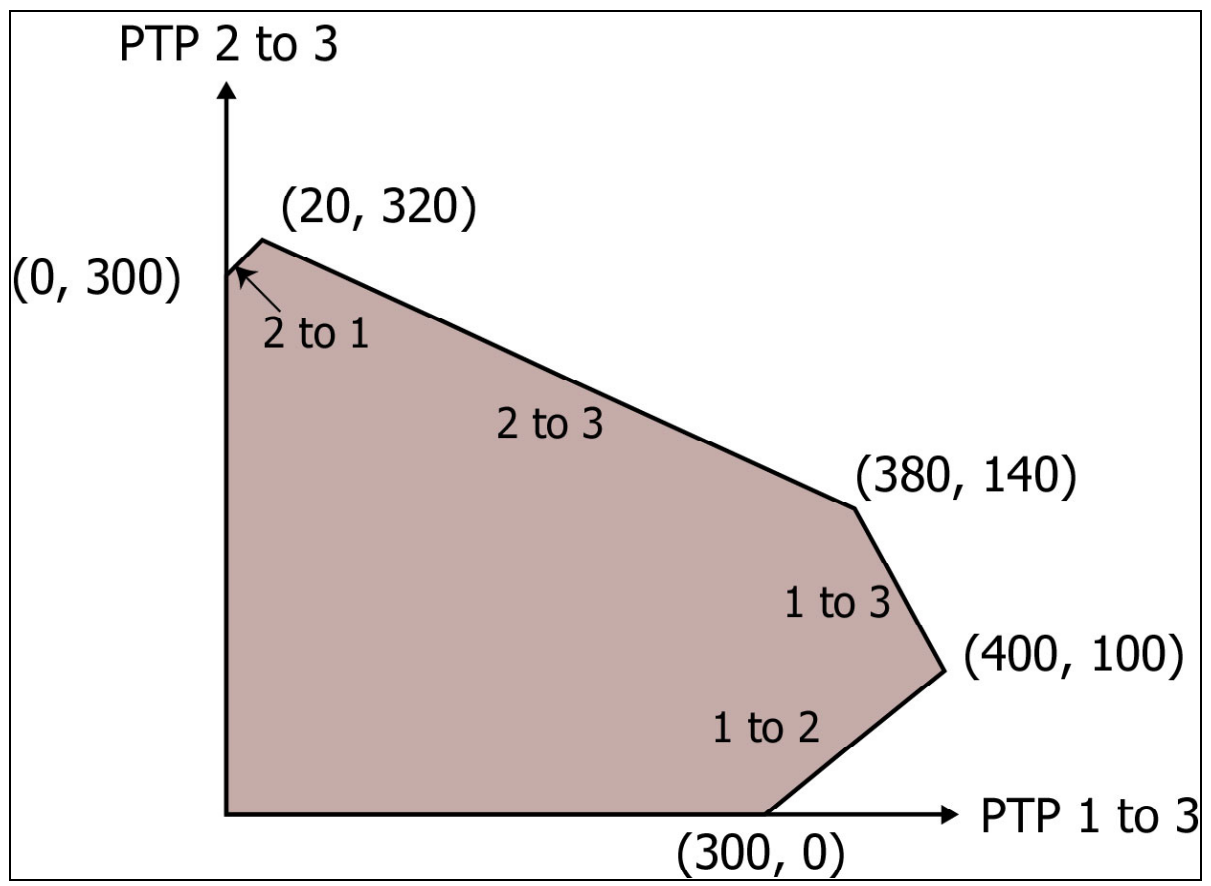

Figure 3. Feasibility Region

\section{Empirical Methodology}

This initial analysis covers only six-month TCCs that were purchased in the four initial auctions in 2000 and 2001. Approximately 70\% of all TCC capacity is initially purchased in the six-month auctions. The price of each contract was compared to the resulting congestion rent that accrued between its POI and POW during its effective period. This analysis does not take into account Stage 2 of the initial auctions or the monthly reconfiguration auctions, in which these six-month TCCs could have been resold or disaggregated. Moreover, the analysis does not consider trading in the secondary market, where the holder of a TCC could sell part or all of a TCC without notifying the NYISO. Data on Stage 2 and the monthly reconfiguration auction are released by the NYISO, but the fear of double counting deterred their consideration here. No information is readily available on the unofficial secondary market. In reality, any gains or losses on the TCC may have been split among various holders during its lifetime. Effectively, the assumption is that the original purchaser of the TCC desired it purely as a hedge against the uncertain congestion costs on a contract to deliver electricity physically. Further, this original purchaser held the TCC for its effective period and collected (or paid) all of the rent associated with it. In other words, the rent collected by TCC owners is compared to the initial purchase price, as if the original purchaser held the TCC exclusively to hedge energy trades for its entire effective period.

The NYISO publishes the results of each auction on its website, including the POI, the POW, the number of MWs in the contract, and the clearing price, in terms of $\$ / \mathrm{MW}$ - 
effective period. ${ }^{7}$ For each TCC awarded, the new owner must pay that clearing price for each MW in the award. Given the POI and POW of each contract, the hourly congestion rent is calculated by subtracting the day-ahead congestion component of the LBMP at the POI from the same at the POW. Hourly LBMP data from the day-ahead market are published on the NYISO website for each zone and bus. These hourly rents are summed at the POI and the POW over the entire effective period to determine the quantityweighted average net congestion rent collected by each TCC:

$$
R_{I, W}^{T}=\frac{\sum_{j=1}^{J} \sum_{t=1}^{T}\left(p_{W}^{t}-p_{I}^{t}\right) \cdot N_{I, W}^{T, j}}{\sum_{j=1}^{J} N_{I, W}^{T, j}}
$$

\section{Equation 5}

This net congestion rent is then compared with the price originally paid for the TCC, $c_{I, W}^{T}$. In particular, we test the hypothesis that the price paid for the TCC effective during time interval $T$ using the information available before this interval starts is an efficient estimator for the congestion rent:

$$
{ }^{T-1} c_{I, W}^{T}=E\left[R_{I, W}^{T} \mid \Omega^{T-1}\right]
$$

\section{Equation 6}

We test this hypothesis via the following regression specification:

$$
R_{I, W}^{T}=\beta_{0}+\beta_{1}{ }^{T-1} c_{I, W}^{T}+\varepsilon^{T}
$$

\section{Equation 7}

In an efficient market, $\beta_{0}$ and $\beta_{1}$ would not be statistically significantly different from 0 and 1 , respectively.

Each of the four auctions analyzed had four rounds, except for the autumn 2000 auction which consisted of two rounds. The number of distinct permutations of POIs and POWs for each of these rounds is displayed below in Table 2. Thus, of all the thousands of possible POI/POW pairs, the most traded in any auction is only 262 (in spring 2001).

Table 2. Number of TCCs Traded in Initial Auctions Between Distinct POI and POW Pairs (Spring 2000 to Autumn 2001)

\begin{tabular}{|c|c|c|c|c|c|}
\hline & Round 1 & Round 2 & Round 3 & Round 4 & Total \\
\hline Spring 2000 & 35 & 45 & 43 & 41 & 75 \\
\hline Autumn 2000 & 111 & 63 & - & - & 141 \\
\hline Spring 2001 & 123 & 122 & 98 & 110 & 262 \\
\hline Autumn 2001 & 89 & 108 & 106 & 93 & 224 \\
\hline
\end{tabular}

\footnotetext{
${ }^{7}$ Virtually all NYISO data used in this paper are available at electricitymarketdata.lbl.gov.
} 


\section{Results and Analysis}

Here, we discuss the results of the NYISO initial TCC auction using the available data between spring 2000 and autumn 2001. For each round in each initial auction, we present summary statistics, calculate the effectiveness of TCCs as hedges for transmission congestion, and estimate the degree to which market participants predicted congestion patterns correctly using TCCs. In order to remove the effect of outlying points, in each case, we perform the analysis by first including and then excluding the furthest $10 \%$ of the points from the locus of zero-profit points. Moreover, in order to avoid weighting TCCs by the number of awards, in Section 4.2, we treat multiple TCCs awarded between any POI/POW pair as a single award. This enables us to weight the various TCC prices and congestion rents equally.

\subsection{Total Awards Analysis}

For each six-month NYISO TCC awarded in an initial auction between spring 2000 and autumn 2001, we determine the price paid (in \$/MW) along with the resulting hourly congestion rent (also in $\$ / \mathrm{MW}$ ) as expressed by Equation 5. Based on these data, we calculate the average price (or equivalently, purchasing cost) and congestion rent during the six-month interval, along with their standard deviations and correlation coefficients (see Table 3 through Table 6). ${ }^{8}$

For a new market such as the NYISO TCC, there are no historical data upon which to base one's perceptions about the relationship between forward and spot prices. A rational prior expectation, however, is that TCC prices will be unbiased estimators of the resulting congestion rents, as explained before. Therefore, the market participants who anticipate congestion to occur in the direction of POI to POW over a given transmission path purchase TCCs, i.e., offer positive prices, while those who expect POW to POI congestion take the opposite position.

Figure 5 through Figure 32 show scatter plots of TCC prices and revenues for all rounds of all four auctions studied here, which total 14 auctions. Examination of the data illustrates that most market participants expected POI to POW congestion, and thus, offered positive prices for TCCs. In line with their expectations, congestion frequently occurred in the direction of POI to POW. Indeed, there was a high correlation between the price paid and rent received. However, the average participant not only predicted the direction of congestion correctly, but also profited from the transaction. ${ }^{9}$ These plots of

\footnotetext{
${ }^{8}$ The average cost and rent reported in these tables have the units $\$ / \mathrm{MW}$ for the six month period. This translates into values ranging from $\$ 0.70 / \mathrm{MWh}$ to $\$ 2.20 / \mathrm{MWh}$, which are consistent with values for congestion.

${ }^{9}$ Market participants "correctly predict congestion" if the sign of the price paid is the same as the sign of the congestion rent received. By contrast, they "profit" if the congestion rent received is greater than the price paid.
} 
the TCC price and the congestion rent together with the $45^{\circ}$ line ${ }^{10}$ illustrates how accurately market participants predicted congestion. For example, in Figure 5, almost $90 \%$ of the data points are in the two quadrants through which the $45^{\circ}$ line passes. This indicates that market participants usually correctly predicted the direction of congestion. Furthermore, except for the Spring 2000 semester, market participants profited in over $50 \%$ of the TCC transactions. This outcome is true even if the $10 \%$ of the points that are furthest away from the $45^{\circ}$ line are eliminated.

Following from Equation 5, the scatter plot of TCC prices and resulting congestion rents should be distributed around the $45^{\circ}$ line. A cursory examination of the scatter plots indicates that most data points appear to lie in the top right quadrant, but below the $45^{\circ}$ line. In order to determine the nature of this relationship, we fit an ordinary least-squares (OLS) regression line to the data. The fitted lines corroborate the bias by typically being above the $45^{\circ}$ line for negative TCC prices and below it for positive TCC prices. Moreover, the hypothesis that the regression slope coefficient is different from 1 (the slope of the $45^{\circ}$ line) is statistically significant at the $99 \%$ level (except in Round 3 of Autumn 2001 when there is no clear relationship). This implies that while the market for TCCs functions well for small hedges, it is less efficient for larger values. In terms of Equation 8 , these results imply that $\beta_{0}>0$ and $\beta_{1}<1$. Consequently, market participants systematically lose money when they try to hedge large congestion risk exposures. ${ }^{11}$

Table 3. NYISO TCC Total Award Auction (Spring 2000)

\begin{tabular}{|c|c|c|c|c|c|}
\hline $100 \%$ Data & Round 1 & Round 2 & Round 3 & Round 4 & All Rounds \\
\hline Average Cost & 1311.75 & 9910.40 & 5975.57 & 10822.09 & 7182.54 \\
\hline Average Rent & 1810.90 & 1515.37 & 2958.26 & 6883.61 & 3282.71 \\
\hline Correlation & 0.58 & 0.68 & 0.75 & 0.39 & 0.61 \\
\hline STDEV of cost & 17739.24 & 13771.58 & 14814.78 & 9351.14 & 14533.90 \\
\hline STDEV of rent & 16080.69 & 18847.05 & 17255.61 & 14945.02 & 16962.44 \\
\hline Ratio of stdev (rent/cost) & 0.91 & 1.37 & 1.16 & 1.60 & 1.17 \\
\hline Total number of awards & 62 & 75 & 76 & 69 & 282 \\
\hline Correct predictions & 55 & 61 & 56 & 50 & 222 \\
\hline$\%$ Correct predictions & $88.71 \%$ & $81.33 \%$ & $73.68 \%$ & $72.46 \%$ & $78.72 \%$ \\
\hline Winners & 31 & 19 & 35 & 27 & 112 \\
\hline$\%$ Winners & $50.00 \%$ & $25.33 \%$ & $46.05 \%$ & $39.13 \%$ & $39.72 \%$ \\
\hline \multicolumn{6}{|l|}{$90 \%$ Data } \\
\hline Average Cost & -420.40 & 9562.79 & 5192.44 & 11079.09 & 6561.88 \\
\hline Average Rent & 748.33 & 463.30 & 1309.00 & 5518.11 & 1986.40 \\
\hline Correlation & 0.48 & 0.67 & 0.82 & 0.47 & 0.62 \\
\hline STDEV of cost & 16081.55 & 13157.90 & 14819.19 & 9229.91 & 14123.85 \\
\hline STDEV of rent & 11284.03 & 15678.54 & 16097.56 & 13462.56 & 14465.23 \\
\hline Ratio of stdev (rent/cost) & 0.70 & 1.19 & 1.09 & 1.46 & 1.02 \\
\hline Total number of awards & 56 & 68 & 68 & 62 & 254 \\
\hline Correct predictions & 49 & 55 & 52 & 47 & 203 \\
\hline$\%$ Correct predictions & $87.50 \%$ & $80.88 \%$ & $76.47 \%$ & $75.81 \%$ & $79.92 \%$ \\
\hline Winners & 29 & 16 & 30 & 22 & 97 \\
\hline$\%$ Winners & $51.79 \%$ & $23.53 \%$ & $44.12 \%$ & $35.48 \%$ & $38.19 \%$ \\
\hline
\end{tabular}

\footnotetext{
${ }^{10}$ This is the locus of all zero-profit points, i.e., those for which the TCC price paid is equal to the congestion rent collected.

${ }^{11}$ If indeed the market participants are over-paying for larger exposures, then it would seem to imply that they could be risk averse. In that case, the efficient relationship between TCC prices and the congestion rents would not be a $45^{\circ}$ line but a concave, non-linear function.
} 
Table 4. NYISO TCC Total Award Auction (Autumn 2000)

\begin{tabular}{|l|r|r|r|}
\hline $\mathbf{1 0 0 \%}$ Data & Round 1 & Round 2 & All Rounds \\
\hline Average Cost & 23900.89 & 6254.97 & 20552.89 \\
\hline Average Rent & 14016.08 & 5283.25 & 12359.18 \\
\hline Correlation & 0.90 & 0.87 & 0.91 \\
\hline STDEV of cost & 16985.67 & 11334.82 & 17486.29 \\
\hline STDEV of rent & 9287.81 & 7360.45 & 9580.76 \\
\hline Ratio of stdev (rent/cost) & 0.55 & 0.65 & 0.55 \\
\hline Total number of awards & 363 & 85 & 448 \\
\hline Correct predictions & 313 & 52 & 365 \\
\hline$\%$ Correct predictions & $86.23 \%$ & $61.18 \%$ & $81.47 \%$ \\
\hline Winners & 112 & 61 & 173 \\
\hline$\%$ Winners & $30.85 \%$ & $71.76 \%$ & $38.62 \%$ \\
\hline 90\% Data & & & \\
\hline Average Cost & 25846.73 & 5543.46 & 21977.05 \\
\hline Average Rent & 14720.35 & 4748.69 & 12819.81 \\
\hline Correlation & 0.92 & 0.88 & 0.93 \\
\hline STDEV of cost & 16220.33 & 11236.56 & 17331.79 \\
\hline STDEV of rent & 9106.53 & 7484.10 & 9644.92 \\
\hline Ratio of stdev (rent/cost) & 0.56 & 0.67 & 0.56 \\
\hline Total number of awards & 327 & 77 & 404 \\
\hline Correct predictions & 284 & 44 & 328 \\
\hline$\%$ Correct predictions & $86.85 \%$ & $57.14 \%$ & $81.19 \%$ \\
\hline Winners & 85 & 57 & 142 \\
\hline$\%$ Winners & $25.99 \%$ & $74.03 \%$ & $35.15 \%$ \\
\hline
\end{tabular}

Table 5. NYISO TCC Total Award Auction (Spring 2001)

\begin{tabular}{|c|c|c|c|c|c|}
\hline $100 \%$ Data & Round 1 & Round 2 & Round 3 & Round 4 & All Rounds \\
\hline Average Cost & $\begin{array}{r}3163.58 \\
\end{array}$ & 2508.23 & $\begin{array}{r}3246.25 \\
\end{array}$ & 3179.82 & 2997.96 \\
\hline Average Rent & 1544.85 & 1394.73 & 1664.20 & 1867.28 & 1601.77 \\
\hline Correlation & 0.82 & 0.71 & 0.87 & 0.81 & 0.81 \\
\hline STDEV of cost & 11840.91 & 8102.64 & 14145.08 & 11656.08 & 11418.09 \\
\hline STDEV of rent & 4900.30 & 4271.15 & 6024.32 & 4276.94 & 4861.50 \\
\hline Ratio of stdev (rent/cost) & 0.41 & 0.53 & 0.43 & 0.37 & 0.43 \\
\hline Total number of awards & 186 & 198 & 150 & 159 & 693 \\
\hline Correct predictions & 129 & 133 & 117 & 122 & 501 \\
\hline$\%$ Correct predictions & $69.35 \%$ & $67.17 \%$ & $78.00 \%$ & $76.73 \%$ & $72.29 \%$ \\
\hline Winners & 104 & 101 & 73 & 81 & 359 \\
\hline$\%$ Winners & $55.91 \%$ & $51.01 \%$ & $48.67 \%$ & $50.94 \%$ & $51.80 \%$ \\
\hline \multicolumn{6}{|l|}{$90 \%$ Data } \\
\hline Average Cost & 1272.65 & 1209.12 & 211.26 & 1528.93 & 1085.94 \\
\hline Average Rent & 959.49 & 993.06 & 528.69 & 1414.03 & 981.47 \\
\hline Correlation & 0.67 & 0.74 & 0.75 & 0.80 & 0.73 \\
\hline STDEV of cost & 5491.41 & 5067.81 & 3956.89 & 6303.44 & 5297.42 \\
\hline STDEV of rent & 3525.43 & 3899.89 & 3697.71 & 3467.13 & 3663.50 \\
\hline Ratio of stdev (rent/cost) & 0.64 & 0.77 & 0.93 & 0.55 & 0.69 \\
\hline Total number of awards & 168 & 179 & 134 & 144 & 625 \\
\hline Correct predictions & 118 & 117 & 103 & 108 & 446 \\
\hline$\%$ Correct predictions & $70.24 \%$ & $65.36 \%$ & $76.87 \%$ & $75.00 \%$ & $71.36 \%$ \\
\hline Winners & 97 & 97 & 70 & 76 & 340 \\
\hline$\%$ Winners & $57.74 \%$ & $54.19 \%$ & $52.24 \%$ & $52.78 \%$ & $54.40 \%$ \\
\hline
\end{tabular}


Table 6. NYISO TCC Total Award Auction (Autumn 2001)

\begin{tabular}{|c|c|c|c|c|c|}
\hline $100 \%$ Data & Round 3 & Round 4 & Round 5 & Round 6 & All Rounds \\
\hline Average Cost & -226.81 & -4491.38 & 426.39 & -175.46 & -1401.39 \\
\hline Average Rent & 789.00 & -2806.34 & 742.35 & 376.60 & -462.13 \\
\hline Correlation & 0.24 & 0.98 & 0.89 & 0.91 & 0.77 \\
\hline STDEV of cost & 9132.35 & 6943.24 & 2427.00 & 1917.55 & 6345.15 \\
\hline STDEV of rent & 2613.84 & 4911.50 & 1772.49 & 1580.04 & 3780.56 \\
\hline Ratio of stdev (rent/cost) & 0.29 & 0.71 & 0.73 & 0.82 & 0.60 \\
\hline Total number of awards & 125 & 229 & 163 & 146 & 663 \\
\hline Correct predictions & 75 & 155 & 107 & 91 & 428 \\
\hline$\%$ Correct predictions & $60.00 \%$ & $67.69 \%$ & $65.64 \%$ & $62.33 \%$ & $64.56 \%$ \\
\hline Winners & 74 & 191 & 121 & 110 & 496 \\
\hline$\%$ Winners & $59.20 \%$ & $83.41 \%$ & $74.23 \%$ & $75.34 \%$ & $74.81 \%$ \\
\hline \multicolumn{6}{|l|}{$90 \%$ Data } \\
\hline Average Cost & 412.42 & -5141.78 & 74.53 & -117.23 & -1666.00 \\
\hline Average Rent & 521.83 & -3354.49 & 478.00 & 406.39 & -824.36 \\
\hline Correlation & 0.88 & 0.99 & 0.82 & 0.80 & 0.98 \\
\hline STDEV of cost & 1829.60 & $\begin{array}{ll}6681.31 \\
\end{array}$ & 1508.46 & 1005.77 & 4759.76 \\
\hline STDEV of rent & 1417.73 & 4693.11 & 1290.70 & 991.70 & 3420.50 \\
\hline Ratio of stdev (rent/cost) & 0.77 & 0.70 & 0.86 & 0.99 & 0.72 \\
\hline Total number of awards & 113 & 200 & 147 & 132 & 592 \\
\hline Correct predictions & 65 & 139 & 95 & 79 & 378 \\
\hline$\%$ Correct predictions & $57.52 \%$ & $69.50 \%$ & $64.63 \%$ & $59.85 \%$ & $63.85 \%$ \\
\hline Winners & 67 & 171 & 112 & 103 & 453 \\
\hline$\%$ Winners & $59.29 \%$ & $85.50 \%$ & $76.19 \%$ & $78.03 \%$ & $76.52 \%$ \\
\hline
\end{tabular}

\subsection{Unique Award Analysis}

In order to weight each distinct TCC equally rather than by the number of awards, here we repeat the analysis of Section 4.1 after discarding multiple instances of each TCC/congestion rent pair. Our concern is that by counting $n$ instances of a given TCC award as $n$ separate data points, we weight the summary statistics by the more heavily traded transmission paths. This not only skews the mean and standard deviation towards those of the high-volume paths, but also might increase (the absolute value of) the correlation between TCC prices and congestion rents. For example, if multiple TCCs are awarded for only a few transmission paths, then their price paid and congestion rents collected artificially increase the correlation coefficient overall.

Overall, the removal of multiple TCC awards does not significantly alter the analysis of Section 4.1 (see Table 7 through Table 10). Indeed, market participants still profit and predict most of the transmission congestion correctly via TCCs (see Figure 33 through Figure 60). At the same time, the fitted OLS regression lines are below the $45^{\circ}$ line for most positive TCC prices paid. ${ }^{12}$ This affirms the finding of Section 4.1 that TCC market participants were systematically unsuccessful at hedging larger risk exposures. ${ }^{13}$

Although we demonstrate that the NYISO TCC market is inefficient in each auction, it could still functioning well over all. Indeed, during any given effective period, there is likely to be a deviation between the price paid and the rent received. However, for the entire data set, the two quantities could still be equal in expectation as market participants learn how to use the instrument more efficiently over time. Cumulative analysis of all the data available reveals that the periodic results obtained earlier are robust over time (see Table 11 and Figure 4). In particular, the fitted OLS regression line is below the $45^{\circ}$

\footnotetext{
${ }^{12}$ This is not true in a few cases where $10 \%$ of the most outlying data are removed.

${ }^{13} \mathrm{We}$ also considered unweighting the TCCs by comparing the total price paid and the total congestion rent collected. However, it made little difference in the results from Section 4.1.
} 
line ${ }^{14}$ for most positive TCC prices indicating that market participants systematically over-pay for large risk exposures. This can also be gauged intuitively from the summary statistics: even though almost two-thirds of the transactions are "winners," the average transaction is a "loser," i.e., results in a TCC price paid that is greater than the congestion rent received.

Since the scatter plot and OLS regression indicate the inefficiency of the TCC market for large congestion risk exposures, we posit that TCCs would also be unsuccessful hedges for geographically distant locations. Using the map of NYISO congestion zones (see Figure 1), we construct a measure of distance between any two POI/POW locations in the control area. We obtain this geographical indicator (GI) by first determining the zones in which the POI and POW are situated and then calculating the number of zonal interfaces between the pair. For example, the GI for the pair of zones "West" and "N.Y.C." is 7. After determining GIs for all pairs of zones (see Table 12), we plot them with the predictive power index (PPI), where

$$
P P I_{I, W}^{T}=\left|R_{I, W}^{T}-c_{I, W}^{T}\right|
$$

\section{Equation 8}

Here, $P P I_{I, W}^{T}$ is the PPI for a duration of length $T$ between POI $I$ and POW $W$. The larger value of $P P I_{I, W}^{T}$, the less accurate the ability of the buyer of a TCC between POI $I$ and POW $W$ to predict congestion. ${ }^{15}$

With the exception of some rounds in the first and last semesters, the results of the geographical analysis indicate a high degree of correlation between the GI and PPI (see Table 14 through Table 17). By plotting the two indices, we determine that the PPI increases, often superlinearly, with the GI (see Figure 61 through Figure 74). TCC markets seem to function relatively well for hedges of intrazonal or adjacent-zone congestion, providing TCC holders with a revenue accurate to within a few thousand dollars per MW (or, less than a dollar per MWh) of the purchase price. As the POI and POW get further apart, however, the discrepancy between the price paid and rent received increases to over a few dollars per MWh. ${ }^{16}$ This relationship indicates that the market for TCCs is not efficient across multiple congestion interfaces.

\footnotetext{
${ }^{14}$ The t-statistics for $\hat{\beta}_{0}$ and $\hat{\beta}_{1}$ are 3.47 and 25.86 , respectively.

${ }^{15}$ Since we use an absolute measure, it may be that it picks up on the correlation between the quantity of transmission capability and the POI/POW distance. The use of a relative measure, e.g., employing a percentage difference, is precluded, however, because it understates (overstates) the severity of large (small) deviations. It is, therefore, not effective at measuring differences between the two quantities.

${ }^{16}$ This relationship is not as convincing for the first and last semesters of trading. We conjecture that trading in the first semester (Spring 2000) was subject to the usual warm-up period in which market participants learned market rules and procedures. Therefore, the prices offered were not indicative of the market participants' true valuations of congestion rents. In Autumn 2001, on the other hand, the NYISO region experienced a drop in electricity consumption as a result of the 11 September attacks, thereby disrupting the relationship between prices paid and rents received. The Autumn 2001 auctions were actually under way on 11 September.
} 
Table 7. NYISO TCC Unique Award Auction (Spring 2000)

\begin{tabular}{|c|c|c|c|c|c|}
\hline $100 \%$ Data & Round 1 & \begin{tabular}{|l} 
Round 2 \\
\end{tabular} & Round 3 & Round 4 & All Rounds \\
\hline Average Cost & 5778.92 & 7370.75 & 3212.19 & 9798.14 & 6586.69 \\
\hline Average Rent & 3677.52 & 3232.28 & 2953.23 & 8273.36 & 4559.69 \\
\hline Correlation & 0.61 & 0.67 & 0.75 & 0.48 & 0.63 \\
\hline STDEV of cost & 15422.06 & 14160.65 & 13188.83 & 10643.84 & 13474.37 \\
\hline STDEV of rent & 17659.46 & 20445.05 & 17311.70 & 18529.78 & 18556.00 \\
\hline Ratio of stdev (rent/cost) & 1.15 & 1.44 & 1.31 & 1.74 & 1.38 \\
\hline Total number of awards & 35 & 45 & 44 & 43 & 167 \\
\hline Correct predictions & 28 & 31 & 29 & 26 & 114 \\
\hline$\%$ Correct predic & $80.00 \%$ & $68.89 \%$ & $65.91 \%$ & $60.47 \%$ & $68.26 \%$ \\
\hline Winners & 15 & 16 & 23 & 20 & 74 \\
\hline \% Winners & $42.86 \%$ & $35.56 \%$ & $52.27 \%$ & $46.51 \%$ & $44.31 \%$ \\
\hline \multicolumn{6}{|l|}{$90 \%$ Data } \\
\hline Average Cost & 5895.63 & 8504.60 & 2467.01 & 8865.76 & 6403.51 \\
\hline Average Rent & 3593.87 & 5024.70 & 2729.53 & 4804.01 & 4038.08 \\
\hline Correlation & 0.59 & 0.50 & 0.71 & 0.49 & 0.57 \\
\hline STDEV of cost & 14619.70 & 12299.56 & 11075.77 & 10719.30 & 12276.57 \\
\hline STDEV of rent & 12398.58 & 13267.84 & 11605.84 & 12071.85 & 12224.73 \\
\hline Ratio of stdev (rent/cost) & 0.85 & 1.08 & 1.05 & 1.13 & 1.00 \\
\hline Total number of awards & 32 & 41 & 40 & 39 & 152 \\
\hline Correct predictions & 25 & 28 & 25 & 23 & 101 \\
\hline$\%$ Correct predictiol & $78.13 \%$ & $68.29 \%$ & $62.50 \%$ & $58.97 \%$ & $66.45 \%$ \\
\hline Winners & 14 & 15 & 22 & 17 & 68 \\
\hline \% Winners & $43.75 \%$ & $36.59 \%$ & $55.00 \%$ & $43.59 \%$ & $44.74 \%$ \\
\hline
\end{tabular}

Table 8. NYISO TCC Unique Award Auction (Autumn 2000)

\begin{tabular}{|l|r|r|r|}
\hline $\mathbf{1 0 0 \%}$ Data & \multicolumn{1}{|c|}{ Round 1 } & Round 2 & All Rounds \\
\hline Average Cost & 2776.78 & 3349.46 & 2980.84 \\
\hline Average Rent & 3300.52 & 3319.79 & 3307.38 \\
\hline Correlation & 0.80 & 0.85 & 0.82 \\
\hline STDEV of cost & 9659.96 & 9076.94 & 9433.94 \\
\hline STDEV of rent & 6461.88 & 6599.08 & 6492.03 \\
\hline Ratio of stdev (rent/cost) & 0.67 & 0.73 & 0.69 \\
\hline Total number of awards & 112 & 62 & 174 \\
\hline Correct predictions & 63 & 31 & 94 \\
\hline \% Correct predictions & $56.25 \%$ & $50.00 \%$ & $54.02 \%$ \\
\hline Winners & 92 & 49 & 141 \\
\hline \% Winners & $82.14 \%$ & $79.03 \%$ & $81.03 \%$ \\
\hline 90\% Data & & & 680.65 \\
\hline Average Cost & 87.82 & 1720.70 & 1954.68 \\
\hline Average Rent & 1663.44 & 2465.63 & 0.80 \\
\hline Correlation & 0.77 & 0.89 & 4512.09 \\
\hline STDEV of cost & 2258.68 & 6779.88 & 4977.03 \\
\hline STDEV of rent & 4267.56 & 6032.49 & 1.10 \\
\hline Ratio of stdev (rent/cost) & 1.89 & 0.89 & 157 \\
\hline Total number of awards & 100 & 57 & 77 \\
\hline Correct predictions & 51 & 26 & 136 \\
\hline \% Correct predictions & $51.00 \%$ & $45.61 \%$ & $86.62 \%$ \\
\hline Winners & 88 & 48 & $49.04 \%$ \\
\hline \% Winners & $88.00 \%$ & $84.21 \%$ & \\
\hline
\end{tabular}


Table 9. NYISO TCC Unique Award Auction (Spring 2001)

\begin{tabular}{|l|r|r|r|r|r|}
\hline 100\% Data & Round 1 & Round 2 & Round 3 & Round 4 & All Rounds \\
\hline Average Cost & 646.30 & 787.87 & 685.84 & 2237.10 & 1077.35 \\
\hline Average Rent & 686.43 & 563.45 & 279.49 & 938.23 & 625.86 \\
\hline Correlation & 0.66 & 0.62 & 0.80 & 0.79 & 0.71 \\
\hline STDEV of cost & 8373.52 & 7448.32 & 10358.42 & 10946.63 & 9280.25 \\
\hline STDEV of rent & 3944.27 & 4110.36 & 4742.90 & 3563.27 & 4083.03 \\
\hline Ratio of stdev (rent/cost) & 0.47 & 0.55 & 0.46 & 0.33 & 0.44 \\
\hline Total number of awards & 124 & 121 & 98 & 110 & 453 \\
\hline Correct predictions & 84 & 79 & 73 & 79 & 315 \\
\hline$\%$ Correct predictions & $67.74 \%$ & $65.29 \%$ & $74.49 \%$ & $71.82 \%$ & $69.54 \%$ \\
\hline Winners & 82 & 68 & 45 & 50 & 245 \\
\hline \% Winners & $66.13 \%$ & $56.20 \%$ & $45.92 \%$ & $45.45 \%$ & $54.08 \%$ \\
\hline 90\% Data & & & & & -204.61 \\
\hline Average Cost & -684.83 & -160.46 & -167.91 & 256.90 & 284.33 \\
\hline Average Rent & 250.76 & 469.77 & 14.61 & 361.05 & 0.80 \\
\hline Correlation & 0.80 & 0.77 & 0.90 & 0.72 & 2884.96 \\
\hline STDEV of cost & 2599.74 & 2609.14 & 3558.16 & 2761.19 & 3109.69 \\
\hline STDEV of rent & 3190.61 & 3279.54 & 3599.19 & 2256.32 & 1.08 \\
\hline Ratio of stdev (rent/cost) & 1.23 & 1.26 & 1.01 & 0.82 & 409 \\
\hline Total number of awards & 112 & 109 & 89 & 99 & 279 \\
\hline Correct predictions & 76 & 67 & 67 & 69 & $68.22 \%$ \\
\hline \% Correct predictions & $67.86 \%$ & $61.47 \%$ & $75.28 \%$ & $69.70 \%$ & 231 \\
\hline Winners & 77 & 64 & 42 & 48 & $56.48 \%$ \\
\hline \% Winners & $68.75 \%$ & $58.72 \%$ & $47.19 \%$ & $48.48 \%$ & \\
\hline
\end{tabular}

Table 10. NYISO TCC Unique Award Auction (Autumn 2001)

\begin{tabular}{|l|r|r|r|r|r|}
\hline 100\% Data & Round 3 & Round 4 & Round 5 & Round 6 & All Rounds \\
\hline Average Cost & -905.24 & -638.18 & 369.34 & 388.68 & -190.18 \\
\hline Average Rent & 812.17 & 18.01 & 737.67 & 730.12 & 555.45 \\
\hline Correlation & 0.11 & 0.96 & 0.91 & 0.95 & 0.48 \\
\hline STDEV of cost & 10306.66 & 4397.91 & 2234.91 & 3201.55 & 5752.73 \\
\hline STDEV of rent & 2604.89 & 3145.90 & 1842.65 & 2331.97 & 2546.99 \\
\hline Ratio of stdev (rent/cost) & 0.25 & 0.72 & 0.82 & 0.73 & 0.44 \\
\hline Total number of awards & 89 & 108 & 104 & 95 & 396 \\
\hline Correct predictions & 58 & 60 & 73 & 63 & 254 \\
\hline$\%$ Correct predictions & $65.17 \%$ & $55.56 \%$ & $70.19 \%$ & $66.32 \%$ & $64.14 \%$ \\
\hline Winners & 62 & 85 & 82 & 73 & 302 \\
\hline \% Winners & $69.66 \%$ & $78.70 \%$ & $78.85 \%$ & $76.84 \%$ & $76.26 \%$ \\
\hline 90\% Data & & & & & 77.44 \\
\hline Average Cost & 583.61 & -293.06 & -25.11 & 142.37 & 477.35 \\
\hline Average Rent & 749.55 & 250.98 & 386.44 & 583.96 & 0.95 \\
\hline Correlation & 0.97 & 0.96 & 0.90 & 0.88 & 1848.60 \\
\hline STDEV of cost & 2391.20 & 2377.29 & 1069.99 & 928.02 & 1705.04 \\
\hline STDEV of rent & 2158.94 & 2109.64 & 1202.39 & 1011.88 & 0.92 \\
\hline Ratio of stdev (rent/cost) & 0.90 & 0.89 & 1.12 & 1.09 & 358 \\
\hline Total number of awards & 80 & 98 & 94 & 86 & 223 \\
\hline Correct predictions & 52 & 51 & 65 & 55 & $62.29 \%$ \\
\hline \% Correct predictions & $65.00 \%$ & $52.04 \%$ & $69.15 \%$ & $63.95 \%$ & 68 \\
\hline Winners & 56 & 78 & 76 & $79.07 \%$ & $77.65 \%$ \\
\hline \% Winners & $70.00 \%$ & $79.59 \%$ & $80.85 \%$ & 79 & \\
\hline
\end{tabular}


Table 11. NYISO TCC Unique Award Auction (All Auctions)

\begin{tabular}{|l|r|}
\hline Average Cost & 1707.18 \\
\hline Average Rent & 1547.26 \\
\hline Correlation & 0.60 \\
\hline STDEV of cost & 9324.63 \\
\hline STDEV of rent & 8062.91 \\
\hline Ratio of stdev (rent/cost) & 0.86 \\
\hline Total number of awards & 1185 \\
\hline Number of correct predictions & 895 \\
\hline$\%$ Correct predictions & $75.53 \%$ \\
\hline Winners & 762 \\
\hline$\%$ Winners & $64.30 \%$ \\
\hline
\end{tabular}

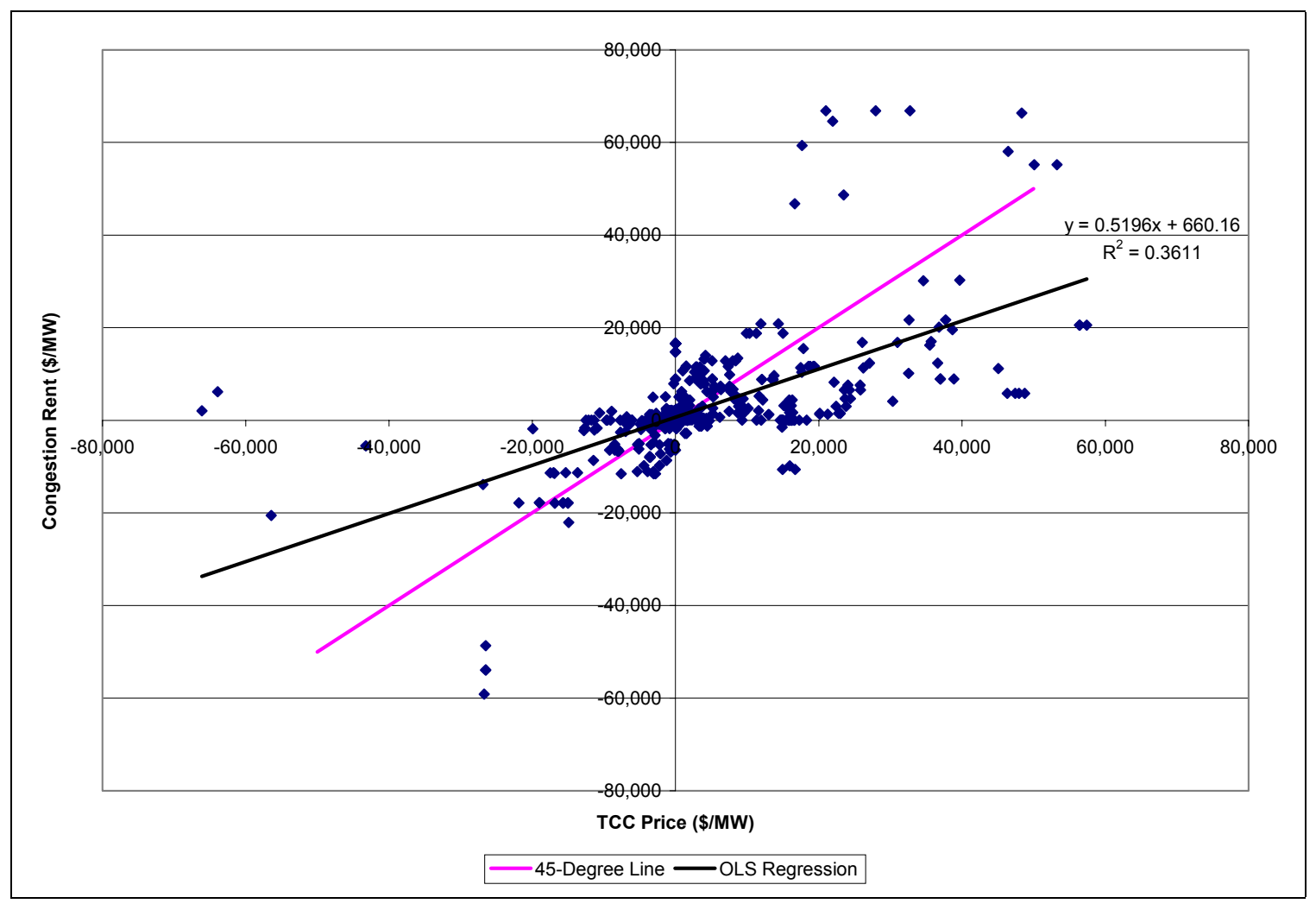

Figure 4. TCC Price Paid and Congestion Rent Collected (100\% Data for All Rounds and Auctions, Unique Awards) 
Table 12. NYISO Geographical Indicator

\begin{tabular}{|c|c|c|c|c|c|c|c|c|c|c|c|c|c|c|c|c|}
\hline & & \multicolumn{15}{|c|}{ POW Zone } \\
\hline & & 1 & 2 & & 4 & 56 & 57 & & 9 & 10 & 11 & & 13 & 14 & 15 & 16 \\
\hline \multirow{16}{*}{$\begin{array}{l}\stackrel{0}{c} \\
\stackrel{0}{\mathbf{N}} \\
\overline{0} \\
\square\end{array}$} & 1 & 0 & 1 & & 4 & & 2 & 5 & 6 & 7 & 8 & 9 & 4 & 5 & 1 & 1 \\
\hline & 2 & 1 & 0 & 1 & 3 & & is & 4 & 5 & 6 & 7 & 9 & 3 & 4 & 2 & 1 \\
\hline & 3 & 2 & 1 & 0 & 2 & & 2 & 3 & 4 & 5 & 6 & 9 & 2 & 3 & 1 & 1 \\
\hline & 4 & 4 & 3 & 2 & 0 & & 2 & 3 & 4 & 5 & 6 & 9 & 2 & 2 & 2 & 3 \\
\hline & 5 & 3 & 2 & 1 & 1 & ) & T & 2 & 3 & 4 & 5 & $\overline{9}$ & 1 & 2 & 1 & \\
\hline & 6 & 4 & 3 & 2 & 1 & ( & 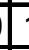 & 2 & 3 & 4 & 5 & 9 & 2 & 1 & 2 & 2 \\
\hline & 7 & 4 & 3 & 2 & 2 & & † & 1 & 2 & 3 & 4 & 9 & 2 & 1 & 2 & \\
\hline & 8 & 5 & 4 & 3 & 3 & 2 & 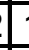 & 0 & 1 & 2 & 3 & 9 & 3 & 2 & 3 & 2 \\
\hline & 9 & 6 & 5 & 4 & 4 & 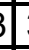 & 2 & 1 & 0 & 1 & 2 & 9 & 4 & 3 & 4 & 2 \\
\hline & 10 & 7 & 6 & 5 & 5 & 7 & 3 & 2 & 1 & 0 & 1 & 9 & 5 & 4 & 5 & 1 \\
\hline & 11 & 8 & 7 & 6 & 6 & & 52 & 3 & 2 & 1 & $\overline{0}$ & 9 & 6 & 5 & 6 & 2 \\
\hline & 12 & 9 & 9 & 9 & 9 & & ts & 9 & 9 & 9 & $\overline{9}$ & 0 & $\overline{9}$ & 9 & 9 & $\overline{9}$ \\
\hline & 13 & 4 & 3 & 2 & 1 & & 2 & 3 & 4 & 5 & 6 & 9 & 0 & 3 & 2 & 2 \\
\hline & 14 & 5 & 4 & 3 & 2 & & T & 2 & 3 & 4 & 5 & 9 & 3 & 0 & 3 & 3 \\
\hline & 15 & & 2 & 1 & 2 & & 2 & 3 & 4 & 5 & 6 & 9 & 2 & 3 & 0 & 2 \\
\hline & 16 & & & & & & & & & 1 & 2 & 9 & 2 & 3 & 2 & 0 \\
\hline
\end{tabular}

Table 13. NYISO Zonal Key

\begin{tabular}{|c|c|}
\hline Zone Number & Zone Name \\
\hline 1 & West \\
\hline 2 & Geneseo \\
\hline 3 & Central \\
\hline 4 & North \\
\hline 5 & Mohawk Valley \\
\hline 6 & Capital \\
\hline 7 & Hudson Valley \\
\hline 8 & Millwood \\
\hline 9 & Dunwoodie \\
\hline 10 & New York City \\
\hline 11 & Long Island \\
\hline 12 & No such zone \\
\hline 13 & Hydro-Québec \\
\hline 14 & New England \\
\hline 15 & Ontario \\
\hline 16 & PJM \\
\hline
\end{tabular}

Table 14. NYISO TCC Geographical Analysis (100\% Data for Spring 2000)

\begin{tabular}{|l|r|r|r|r|r|}
\hline $\mathbf{1 0 0 \%}$ Data & \multicolumn{1}{|c|}{ Round 1 } & Round 2 & Round 3 & Round 4 & \multicolumn{1}{c|}{ All Rounds } \\
\hline GI-PPI Correlation & 0.01 & 0.39 & 0.26 & 0.46 & 0.29 \\
\hline Avg PPI for GI of 0 & 7808.49 & 7903.84 & 6468.21 & 5225.97 & 6721.36 \\
\hline Avg PPI for GI of 1 & 16856.29 & 16195.20 & 6265.14 & 16145.58 & 14798.33 \\
\hline Avg PPI for GI of 2 & 13043.03 & 15597.16 & 12324.51 & 21752.76 & 16211.82 \\
\hline Avg PPI for GI of 3 & 10187.15 & 12958.78 & 12833.76 & 15300.51 & 13121.64 \\
\hline Avg PPI for GI of 4+ & 10873.33 & 20335.84 & 12157.66 & 18428.32 & 15607.75 \\
\hline Avg PPI & 12084.36 & 13050.25 & 8253.24 & 12110.95 & 11360.69 \\
\hline
\end{tabular}


Table 15. NYISO TCC Geographical Analysis (100\% Data for Autumn 2000)

\begin{tabular}{|l|r|r|r|}
\hline & \multicolumn{1}{|l|}{ Round 1 } & \multicolumn{1}{l|}{ Round 2 } & \multicolumn{1}{|l|}{ All Rounds } \\
\hline GI-PPI Correlation & 0.42 & 0.45 & 0.42 \\
\hline Avg PPI for GI of 0 & 1953.12 & 1436.48 & 1753.93 \\
\hline Avg PPI for GI of 1 & 3444.58 & 3164.47 & 3351.21 \\
\hline Avg PPI for GI of 2 & 4890.16 & 4773.73 & 4862.58 \\
\hline Avg PPI for GI of 3 & 8022.56 & 2386.91 & 7083.29 \\
\hline Avg PPI for GI of 4+ & 8712.89 & 5963.49 & 6945.42 \\
\hline Avg PPI & 3579.30 & 2899.98 & 3337.24 \\
\hline
\end{tabular}

Table 16. NYISO TCC Geographical Analysis (100\% Data for Spring 2001)

\begin{tabular}{|l|r|r|r|r|r|}
\hline & Round 1 & Round 2 & Round 3 & Round 4 & All Rounds \\
\hline GI-PPI Correlation & 0.51 & 0.26 & 0.68 & 0.56 & 0.52 \\
\hline Avg PPI for GI of 0 & 1923.55 & 2248.81 & 1367.53 & 1343.85 & 1765.27 \\
\hline Avg PPI for GI of 1 & 1431.81 & 2054.89 & 1380.97 & 2885.19 & 1970.84 \\
\hline Avg PPI for GI of 2 & 4099.12 & 4659.81 & 7728.00 & 8359.57 & 5723.79 \\
\hline Avg PPI for GI of 3 & 5049.84 & 4547.16 & 3824.80 & 12459.07 & 6710.71 \\
\hline Avg PPI for GI of 4+ & 24748.11 & 15439.93 & 35883.51 & 24411.42 & 25012.55 \\
\hline Avg PPI & 2729.26 & 2718.06 & 2580.38 & 3423.23 & 2861.63 \\
\hline
\end{tabular}

Table 17. NYISO TCC Geographical Analysis (100\% Data for Autumn 2001)

\begin{tabular}{|l|r|r|r|r|r|}
\hline & Round 3 & Round 4 & Round 5 & Round 6 & All Rounds \\
\hline GI-PPI Correlation & -0.07 & 0.39 & 0.19 & 0.18 & 0.01 \\
\hline Avg PPI for GI of 0 & 3477.65 & 731.04 & 608.91 & 676.45 & 1410.16 \\
\hline Avg PPI for GI of 1 & 523.05 & 1202.39 & 650.86 & 618.68 & 800.74 \\
\hline Avg PPI for GI of 2 & 292.89 & 646.34 & 837.27 & 1058.57 & 780.72 \\
\hline Avg PPI for GI of 3 & 1943.52 & 1361.23 & 1030.56 & 735.49 & 1201.17 \\
\hline Avg PPI for GI of 4+ & 1981.93 & 3386.67 & 1134.80 & 1337.14 & 2043.57 \\
\hline Avg PPI & 2223.56 & 1075.85 & 699.15 & 780.38 & 1165.93 \\
\hline
\end{tabular}

\subsection{Comparison With Established Forwards Trading}

Overall, market participants in NYISO TCC auctions seem to predict the direction and severity of congestion with reasonable success. However, data analysis from the first two years of trading indicates that the NYISO TCC market is less helpful to TCC buyers in hedging congestion risk that is either large (worth more than $\$ 1 / \mathrm{MWh}$, or $\$ 4380 / \mathrm{MW}$ ) or spread across multiple transmission congestion interfaces. Perhaps due to the way in which TCCs are defined, their prices do not reflect the congestion rents received for larger exposures. As a result, market participants consistently predict transmission congestion incorrectly while using TCCs for hedging all but the most straightforward exposures. 
The NYISO TCC market's PTP system is based on forward trading of thousands of different POI/POW permutations. Therefore, trading is thinner and opportunities for efficient price discovery weak. Further, TCCs are defined in a rigid way, i.e., a fixed capacity over a fixed period, with high transactions costs involved in disaggregating them in the secondary market. This makes TCC trading more difficult for market participants. Alternatively, in more compact markets, risk management is more straightforward because the forward positions required to hedge against a given spot market exposure are immediate. Moreover, because TCC prices are based on an artificial congestion pattern verified as feasible but not necessarily likely at the time of the auction, actual congestion patterns will differ leaving TCCs mispriced. Since actual PTP transfer capability depends on the actual power flows, or at least those seen in day-ahead trading, secondary trading of TCCs is limited, resulting in illiquidity. This attribute makes it difficult to hedge using PTP instruments such as NYISO TCCs without ex ante knowledge of transmission congestion. Such obfuscation is the likely cause of the poor performance of NYISO TCC markets, as indicated by the data in Sections 4.1 and 4.2.

\section{Conclusions}

The debate over the nature of electricity industry restructuring has loosely divided analysts into two camps supporting centralized versus decentralized paradigms. While the former relies on a central authority to be responsible for operations and organized markets, the latter leaves most decisions to be resolved in autonomous markets. Within the context of transmission congestion management, the more centralized paradigm tends to use a PTP approach by defining rights to the congestion rent collected between POIPOW pairs, and allocating such financial rights to holders of historic transmission rights. While such PTP rights potentially provide a perfect hedge for a transaction between the corresponding nodes, the pricing of such rights in poorly functioning markets may have little to do with their realized value. Thus, market participants will have difficulty hedging congestion risk of a transaction at the right price; that is, while a perfect hedge may be possible, the price paid for it could be exorbitant. By contrast, the flowgate-based trading offers a more decentralized approach by defining a small number of highly liquid rights. Market participants then select the desired flowgates on which to hedge and adjust their portfolio of rights to track congestion patterns.

In order to examine the performance of a system employing the PTP approach, we empirically analyze the NYISO TCC market, using publicly available data from 2000 and 2001 on TCC prices paid and congestion rents collected by market participants. We find that by some simple measures the market performs well. For example, buyers of TCCs predict congestion correctly most of the time. However, the TCC market does not appear efficient at hedging complex transactions, i.e., those involving larger exposures roughly of greater than $\$ 1 / \mathrm{MWh}$ or across multiple congestion interfaces. Particularly, we obtain a robust result that prices and revenues are consistently biased in one direction, with TCC buyers paying prices for expensive TCCs far in excess of any reasonable risk premium. Furthermore, cumulative analysis of the entire two-year data set indicates no evidence of market participants learning how to use the instrument more efficiently over time. 
For future work, we would like to examine the efficiency of transmission congestion risk management in other deregulated electricity industries, such as ERCOT and that of the Pennsylvania-Maryland-New Jersey (PJM) Interconnection. Whereas the latter employs a PTP approach similar to New York's, the former uses flowgate rights to manage congestion. Although our empirical evidence suggests otherwise, it could simply be that the disconnect between TCC prices and congestion rents is symptomatic of a new market with rules that are unfamiliar to most participants. In fact, arbitraging away price differences in electricity markets may not be possible because of illiquidity and risk aversion as well as fear of regulatory action. Indeed, arbitrage could often be confused for market manipulation, thereby allowing inefficiencies to remain. Towards that end, we could also determine if the relationship between TCC prices and congestion rents implies that market participants are risk averse, i.e., if instead of the $45^{\circ}$ line, a concave, non-linear function is the best fit to the data. The geographical analysis could also be enhanced by including indicator variables in the OLS regressions for various NYISO areas to determine which zones enable better hedging. Employing a geographical information system (GIS) would also increase the robustness of the results by enabling the creation of more accurate geographical indicators. Another topic to pursue would be to determine actual hedging strategies for NYISO TCC market participants using the optimal risk hedging strategies. Finally, for completeness, it would be interesting to include the reconfiguration auctions and the secondary market into our analysis of the NYISO TCC.

\section{References}

Audet, N., P. Heiskanen, J. Keppo, and I. Vehviläinen (2002), "Modeling of Electricity Forward Curve Dynamics," working paper, University of Michigan, $<$ http://wwwpersonal.engin.umich.edu/ keppo/ForwardDynamics.pdf $>$.

Bushnell, J. (1997), "Transmission Rights and Market Power," The Electricity Journal, 12(8): 77-85.

Bushnell, J. and S.E. Stoft (1997), "Improving Private Incentives for Electric Grid Investment," Resource and Energy Economics, 19:85-108.

Chao, H.-P. and S.C. Peck (1996), "A Market Mechanism for Electric Power Transmission," Journal of Regulatory Economics, 10(1): 25-59.

Chao, H.-P. and S.C. Peck (1997), "Institutional Design for an Electricity Contract Market with Central Dispatch," The Energy Journal, 18(1): 85-110.

Chao, H.-P. and S.C. Peck (1998), "Reliability Management in Competitive Electricity Markets," Journal of Regulatory Economics, 14(2): 189-200.

Chao, H.-P., S.C. Peck, S.S. Oren, and R.B. Wilson (2000), "Flow-Based Transmission Rights and Congestion Management," The Electricity Journal, 13(8): 38-58.

Harvey, S.M., W.W. Hogan, and S.L. Pope (1996), "Transmission Capacity Reservations and Transmission Congestion Contracts," mimeo, Harvard University.

Hogan, W.W. (1992), "Contract Networks for Electric Power Transmission," Journal of Regulatory Economics, 4(3): 211-42.

Joskow, P.L. (1997), "Restructuring, Competition, and Regulatory Reform in the U.S. Electricity Sector," Journal of Economic Perspectives, 11(3): 119-138. 
Joskow, P.L. and J. Tirole (2000), "Transmission Rights and Market Power in Electric Power Networks," Rand Journal of Economics, 31(3): 450-487.

Kolstad, C.D. (2000), Environmental Economics, Oxford University Press, New York, NY, USA.

Luenberger, D.G. (1997), Investment Science, Oxford University Press, New York, NY, USA.

New York Independent System Operator (2000), "Open Access Transmission Tariff," Federal Energy Regulatory Commission Filing Docket No. RM99-12-000, $<$ http://www.nyiso.com/services/documents/filings/pdf/oatt/body_oatt.pdf $>$.

Oren, S.S. (1997a), "Economic Inefficiency of Passive Transmission Rights in Congested Electricity Systems with Competitive Generation," The Energy Journal, 18(1): 63-84.

Oren, S.S. (1997b), "Passive Transmission Rights Will Not Do the Job," The Electricity Journal, 10(5): 22-33.

Stoft, S. (1999), "Financial Transmission Rights Meet Cournot," The Energy Journal, 20(1): $1-23$.

Stoft, S. (2002), Power System Economics, IEEE Press, Piscataway, NJ, USA, Ch. 5-9.

Wilson, R.B. (2002), "Architecture of Power Markets," Econometrica, 70(4): 1299-1340.

Wolak, F.A. (2000), "Market Design and Price Behavior in Restructured Electricity Markets: An International Comparison," in Pricing in Competitive Electricity Markets, edited by A. Faruqui and K. Eakin, Kluwer Academic Publishers, Boston, MA, USA. 


\section{Appendix}

\section{Summary of Auctions}

Table 18. Summary of NYISO Initial TCC Auctions, 2000 and 2001

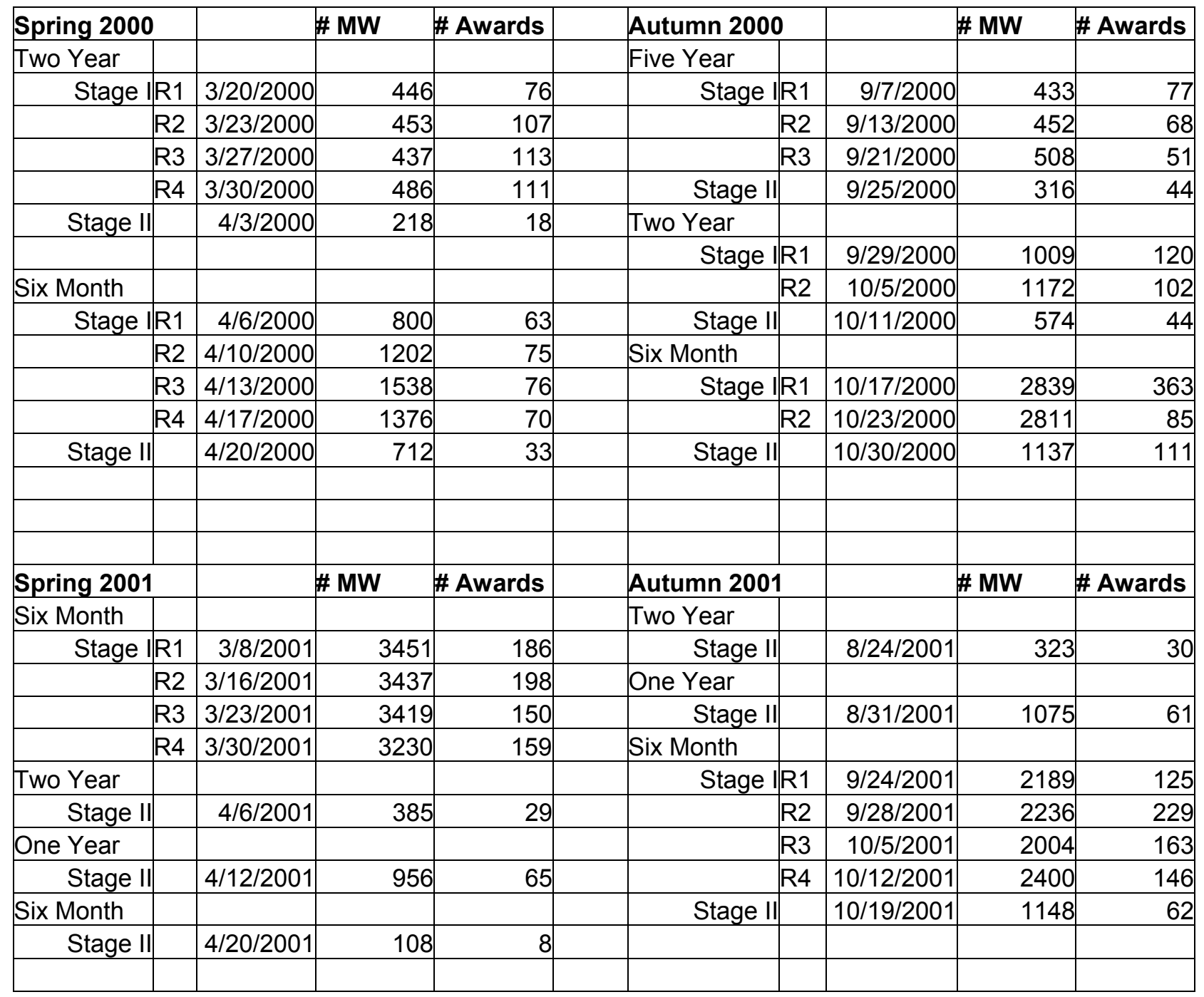


Total Award Auction

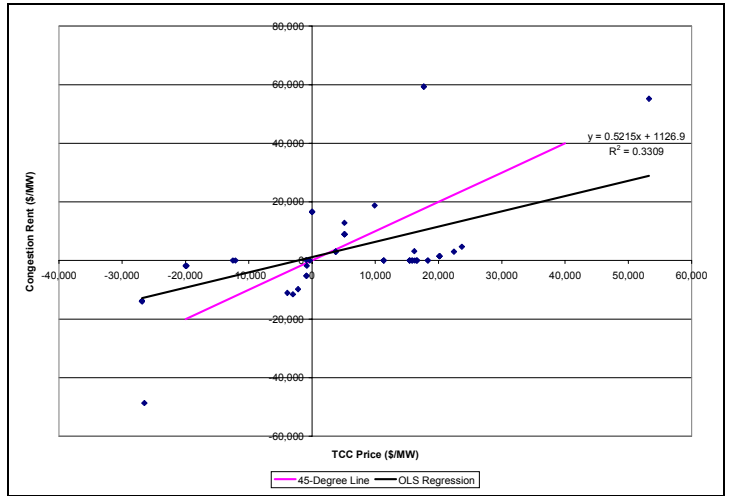

Figure 5. TCC Price Paid and Congestion Rent Collected (100\% Data for Round 1 Spring 2000 Total Award Auction)

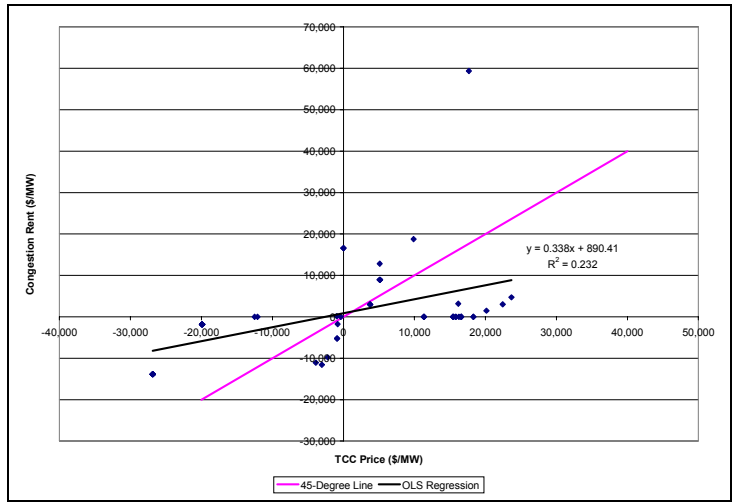

Figure 6. TCC Price Paid and Congestion Rent Collected $(90 \%$ Data for Round 1 Spring 2000 Total Award Auction)

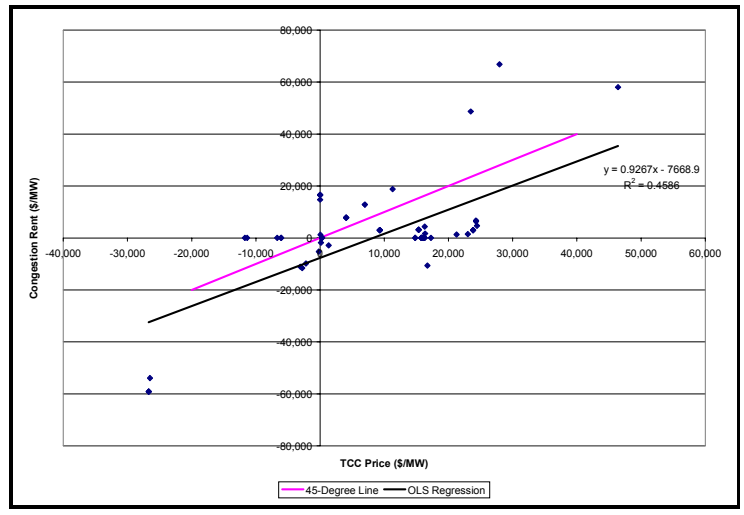

Figure 7. TCC Price Paid and Congestion Rent Collected (100\% Data for Round 2 Spring 2000 Total Award Auction)

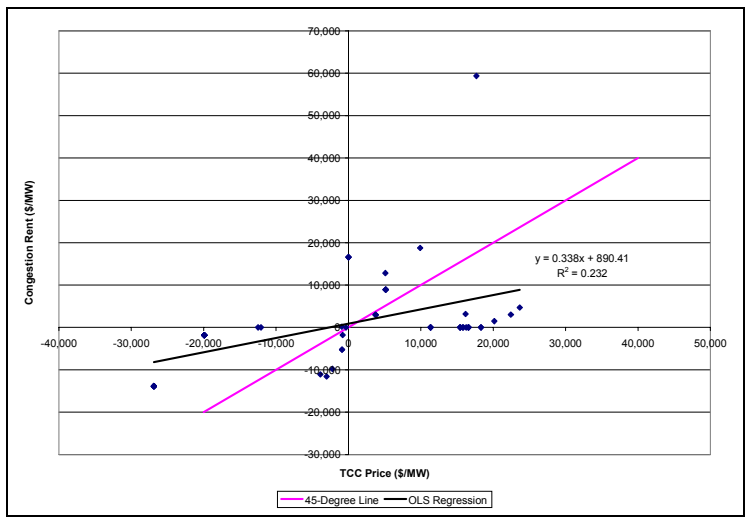

Figure 8. TCC Price Paid and Congestion Rent Collected $(\mathbf{9 0 \%}$ Data for Round 2 Spring 2000 Total Award Auction)

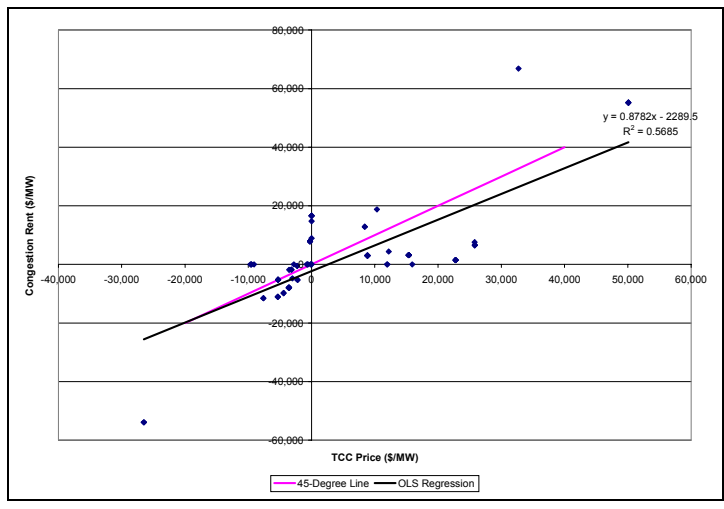

Figure 9. TCC Price Paid and Congestion Rent Collected (100\% Data for Round 3 Spring 2000 Total Award Auction)

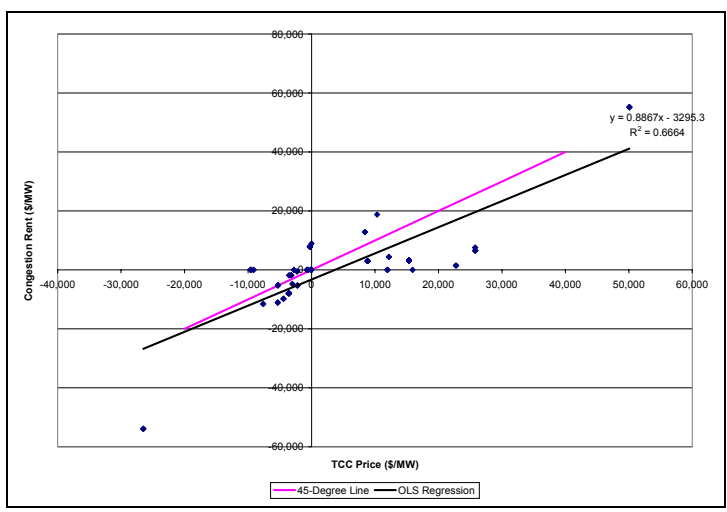

Figure 10. TCC Price Paid and Congestion Rent Collected $(90 \%$ Data for Round 3 Spring 2000 Total Award Auction) 


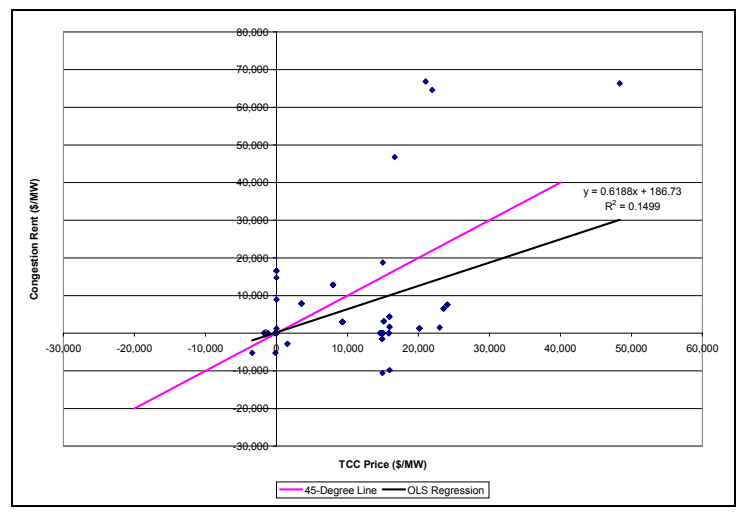

Figure 11. TCC Price Paid and Congestion Rent Collected (100\% Data for Round 4 Spring 2000 Total Award Auction)

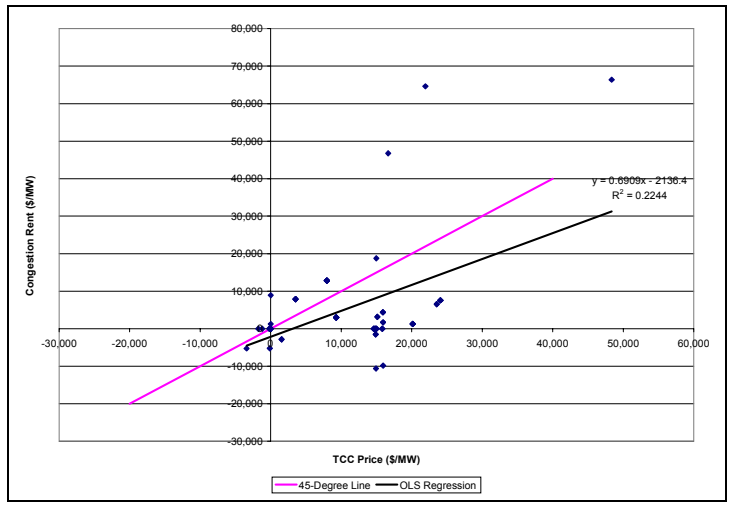

Figure 12. TCC Price Paid and Congestion Rent Collected $\mathbf{9 0 \%}$ Data for Round 4 Spring 2000 Total Award Auction)

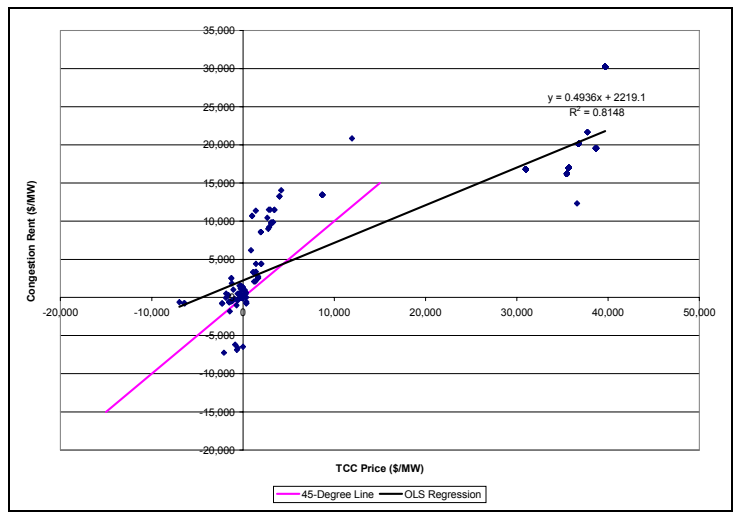

Figure 13. TCC Price Paid and Congestion Rent Collected (100\% Data for Round 1 Autumn 2000 Total Award Auction)

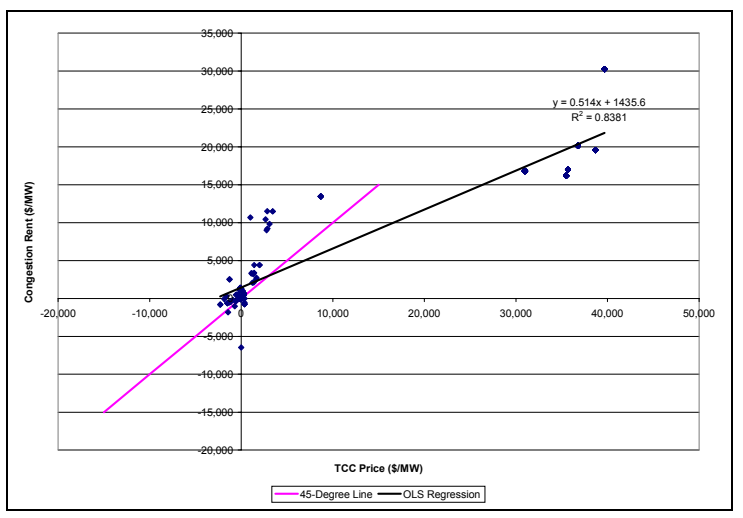

Figure 14. TCC Price Paid and Congestion Rent Collected $\mathbf{9 0 \%}$ Data for Round 1 Autumn 2000 Total Award Auction)

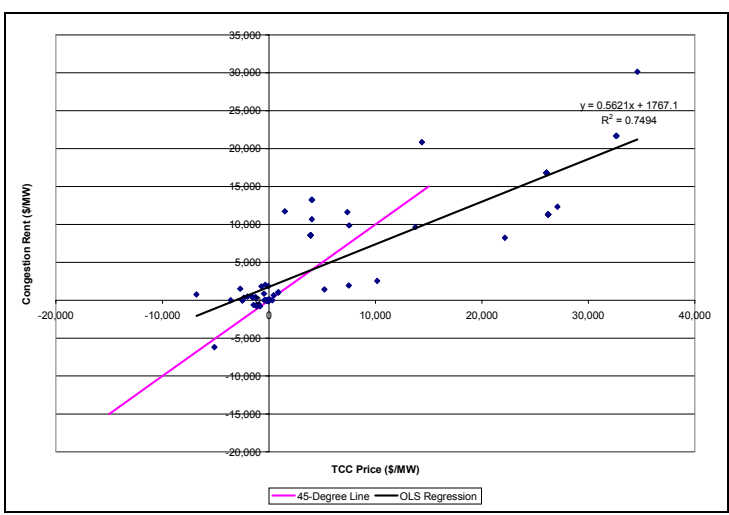

Figure 15. TCC Price Paid and Congestion Rent Collected (100\% Data for Round 2 Autumn 2000 Total Award Auction)

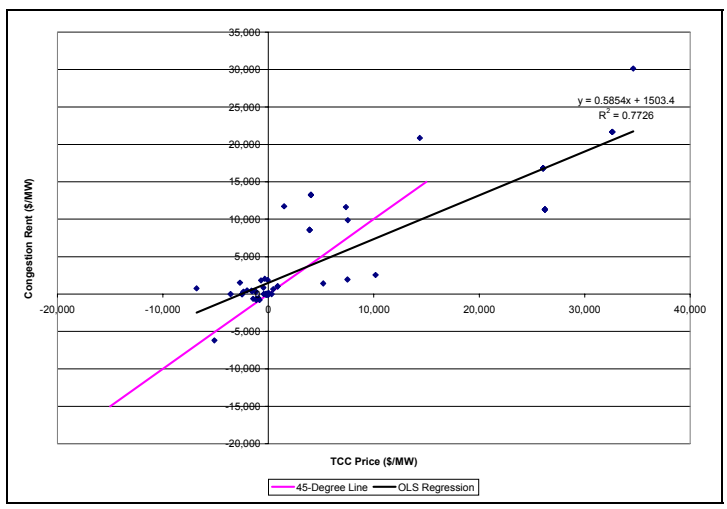

Figure 16. TCC Price Paid and Congestion Rent Collected $\mathbf{9 0 \%}$ Data for Round 2 Autumn 2000 Total Award Auction) 


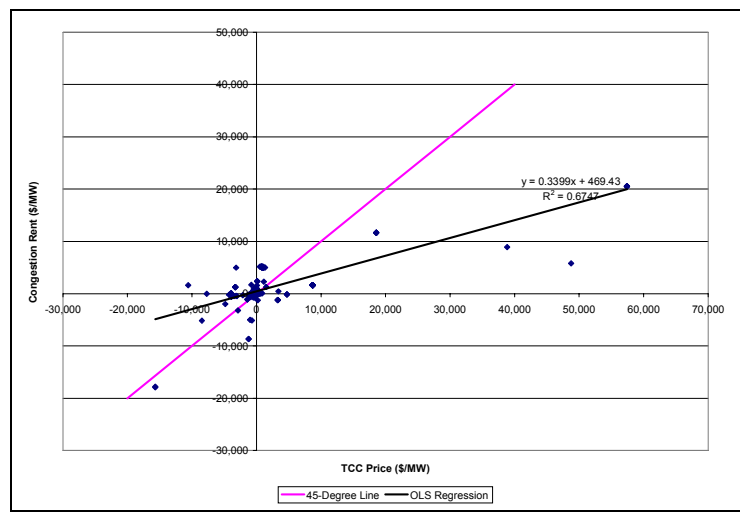

Figure 17. TCC Price Paid and Congestion Rent Collected (100\% Data for Round 1 Spring 2001 Total Award Auction)

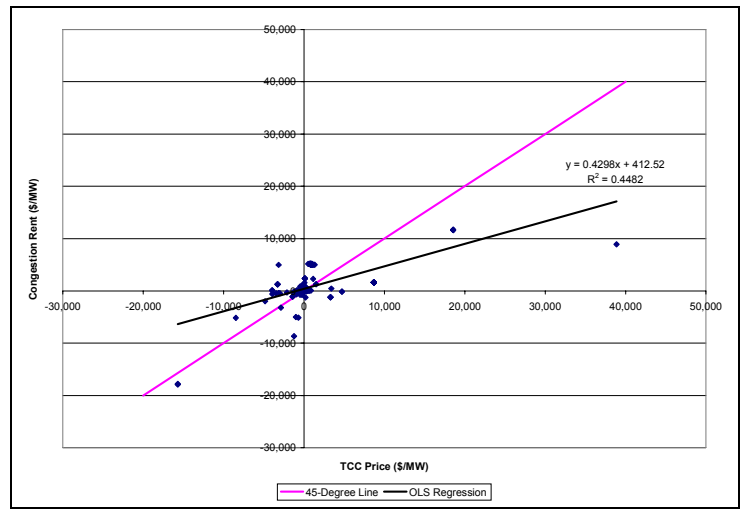

Figure 18. TCC Price Paid and Congestion Rent Collected $(90 \%$ Data for Round 1 Spring 2001 Total Award Auction)

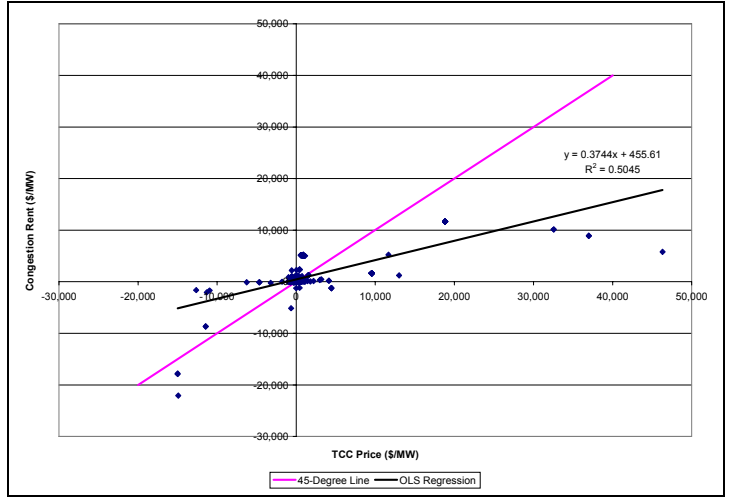

Figure 19. TCC Price Paid and Congestion Rent Collected (100\% Data for Round 2 Spring 2001 Total Award Auction)

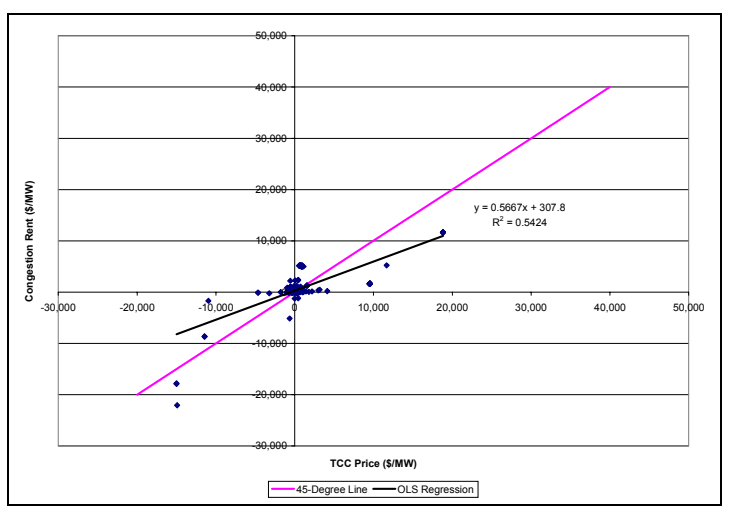

Figure 20. TCC Price Paid and Congestion Rent Collected $\mathbf{9 0 \%}$ Data for Round 2 Spring 2001 Total Award Auction)

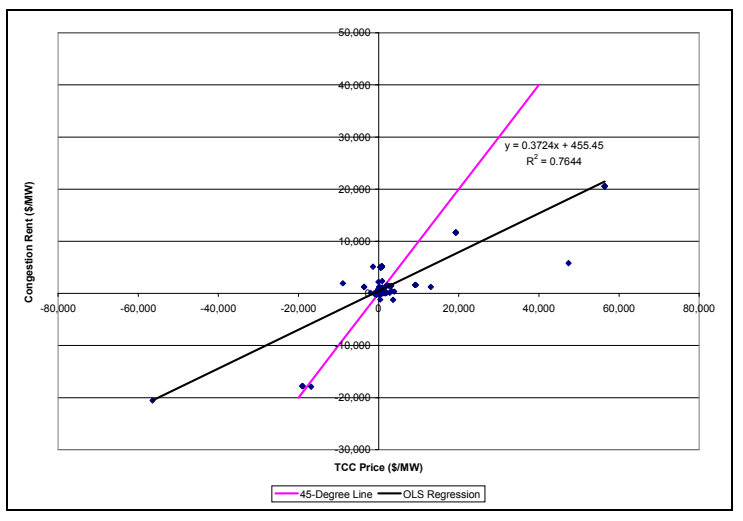

Figure 21. TCC Price Paid and Congestion Rent Collected (100\% Data for Round 3 Spring 2001 Total Award Auction)

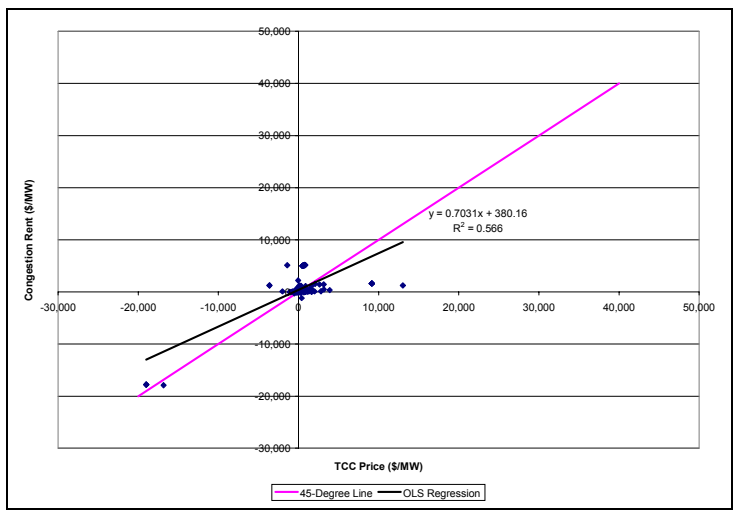

Figure 22. TCC Price Paid and Congestion Rent Collected $\mathbf{9 0 \%}$ Data for Round 3 Spring 2001 Total Award Auction) 


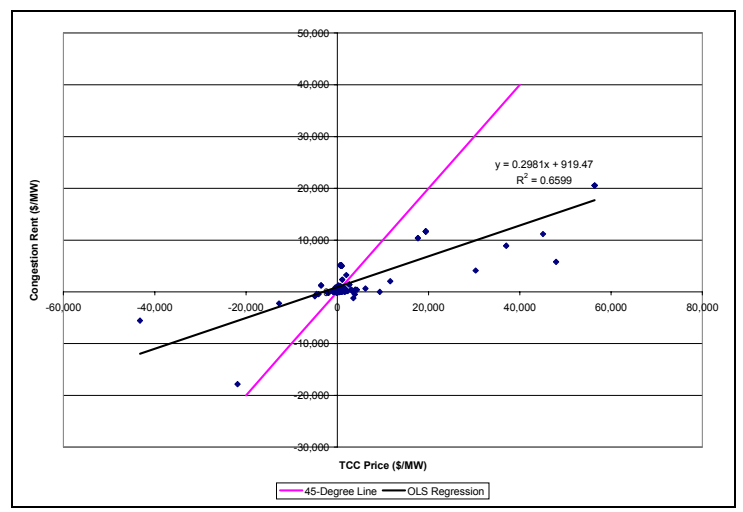

Figure 23. TCC Price Paid and Congestion Rent Collected (100\% Data for Round 4 Spring 2001 Total Award Auction)

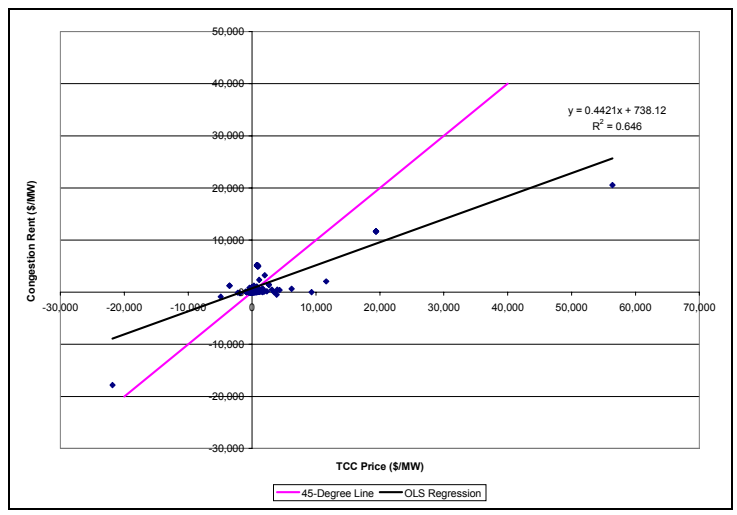

Figure 24. TCC Price Paid and Congestion Rent Collected $(90 \%$ Data for Round 4 Spring 2001 Total Award Auction)

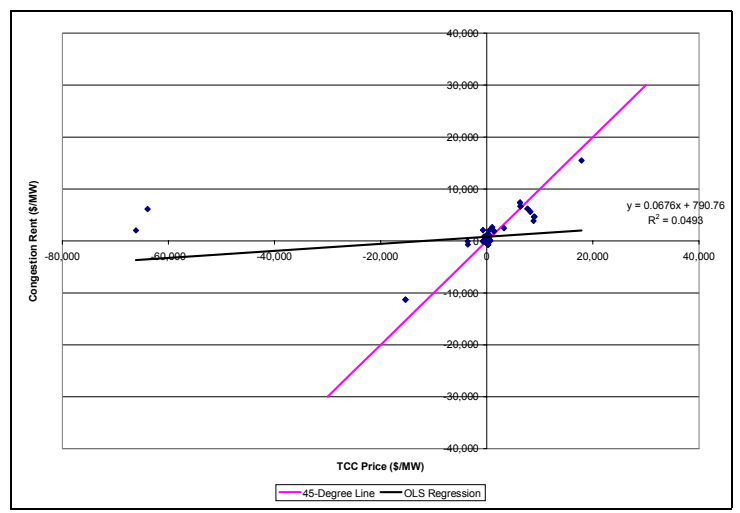

Figure 25. TCC Price Paid and Congestion Rent Collected (100\% Data for Round 3 Autumn 2001 Total Award Auction)

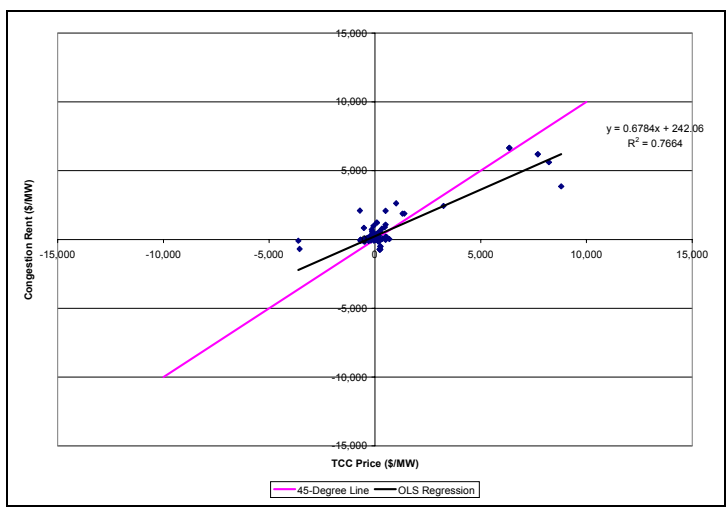

Figure 26. TCC Price Paid and Congestion Rent Collected $\mathbf{9 0 \%}$ Data for Round 3 Autumn 2001 Total Award Auction)

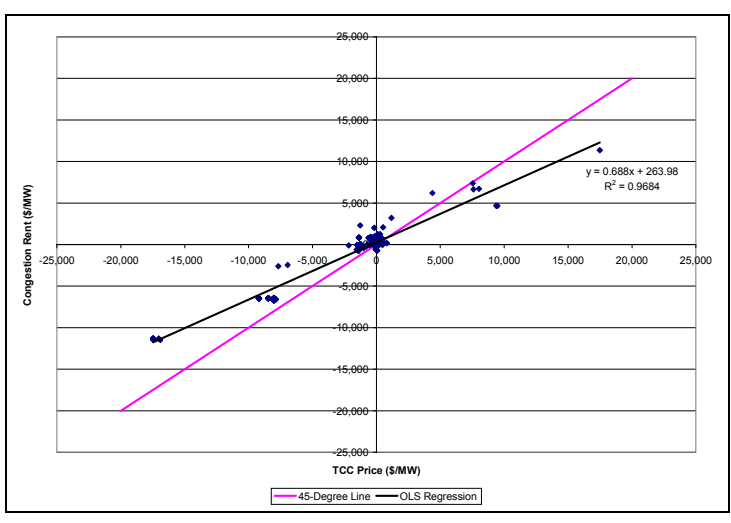

Figure 27. TCC Price Paid and Congestion Rent Collected (100\% Data for Round 4 Autumn 2001 Total Award Auction)

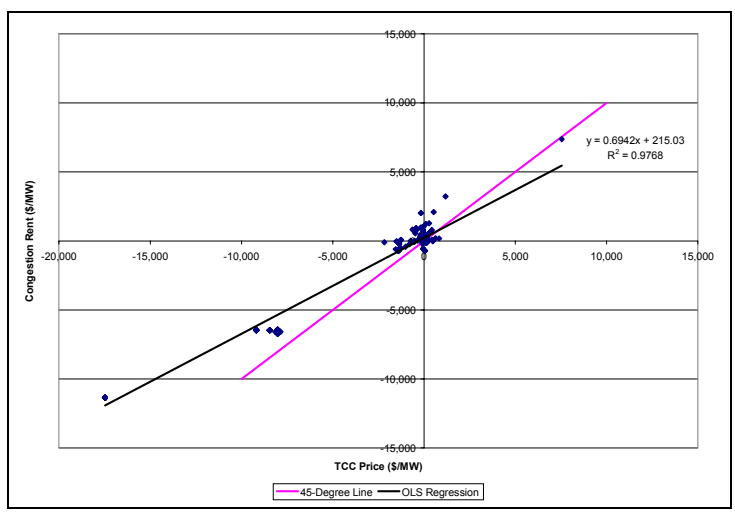

Figure 28. TCC Price Paid and Congestion Rent Collected $\mathbf{9 0 \%}$ Data for Round 4 Autumn 2001 Total Award Auction) 


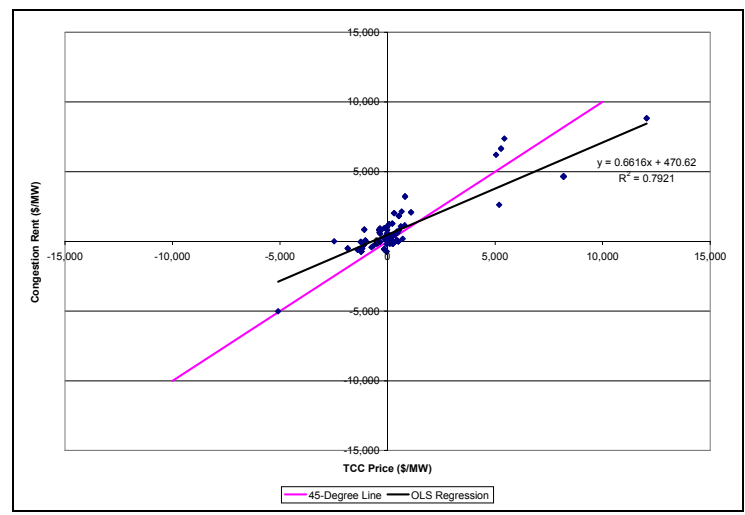

Figure 29. TCC Price Paid and Congestion Rent Collected (100\% Data for Round 5 Autumn 2001 Total Award Auction)

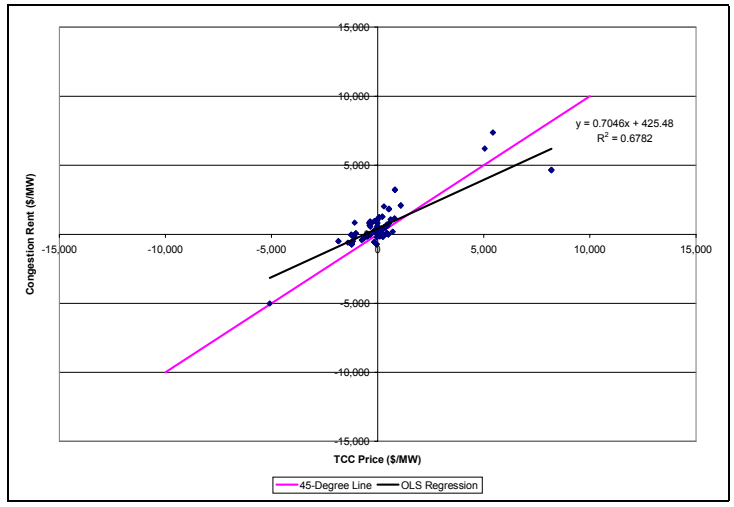

Figure 30. TCC Price Paid and Congestion Rent Collected $\mathbf{9 0} \%$ Data for Round 5 Autumn 2001 Total Award Auction)

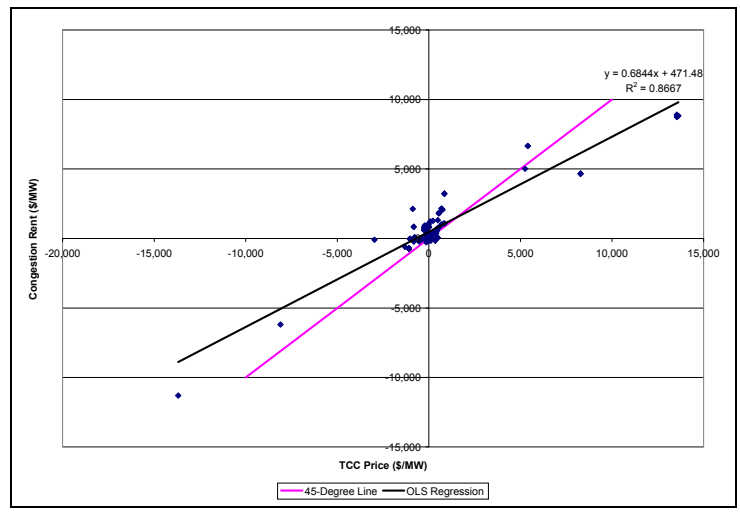

Figure 31. TCC Price Paid and Congestion Rent Collected (100\% Data for Round 6 Autumn 2001 Total Award Auction)

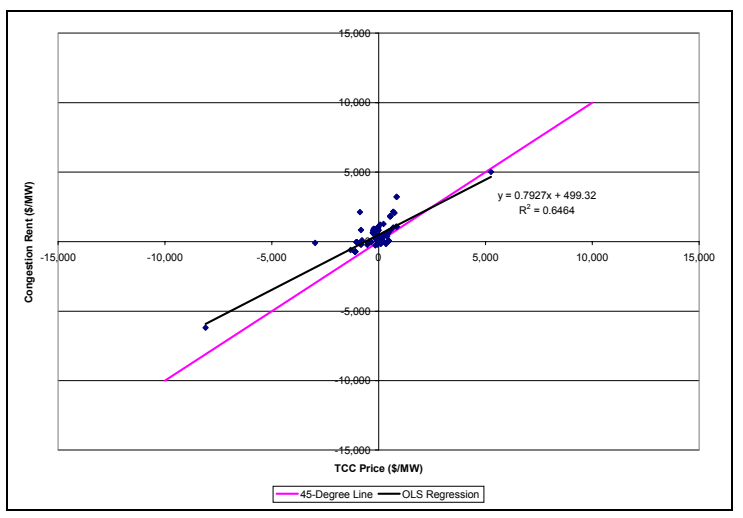

Figure 32. TCC Price Paid and Congestion Rent Collected $\mathbf{9 0 \%}$ Data for Round 6 Autumn 2001 Total Award Auction)

\section{Unique Award Analysis}

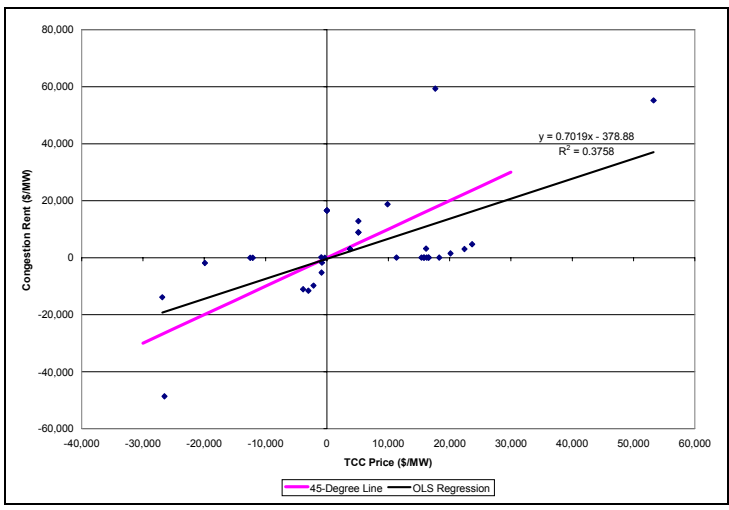

Figure 33. TCC Price Paid and Congestion Rent Collected (100\% Data for Round 1 Spring 2000 Unique Award Auction)

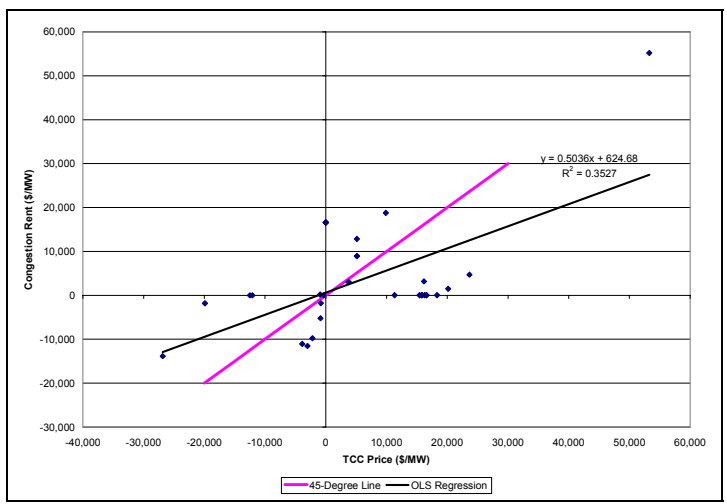

Figure 34. TCC Price Paid and Congestion Rent Collected (90\% Data for Round 1 Spring 2000 Unique Award Auction) 


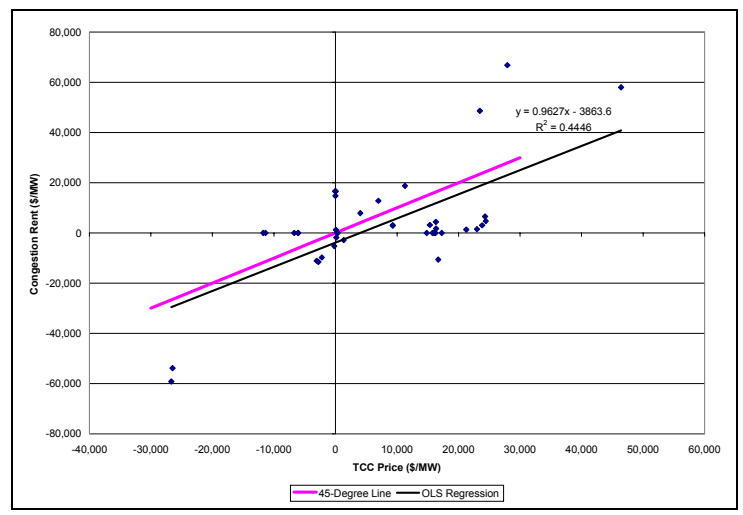

Figure 35. TCC Price Paid and Congestion Rent Collected (100\% Data for Round 2 Spring 2000 Unique Award Auction)

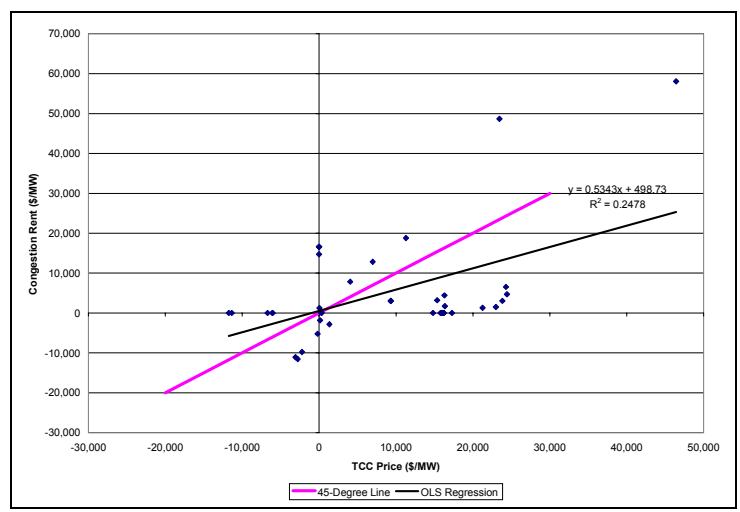

Figure 36. TCC Price Paid and Congestion Rent Collected $(90 \%$ Data for Round 2 Spring 2000 Unique Award Auction)

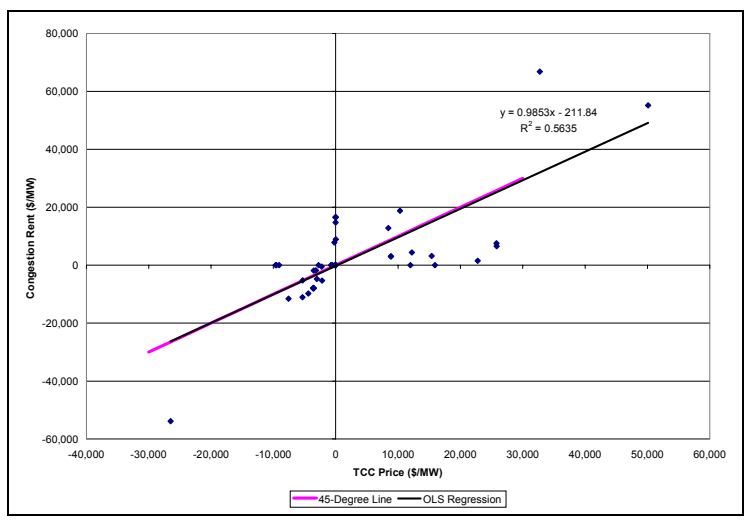

Figure 37. TCC Price Paid and Congestion Rent Collected (100\% Data for Round 3 Spring 2000 Unique Award Auction)

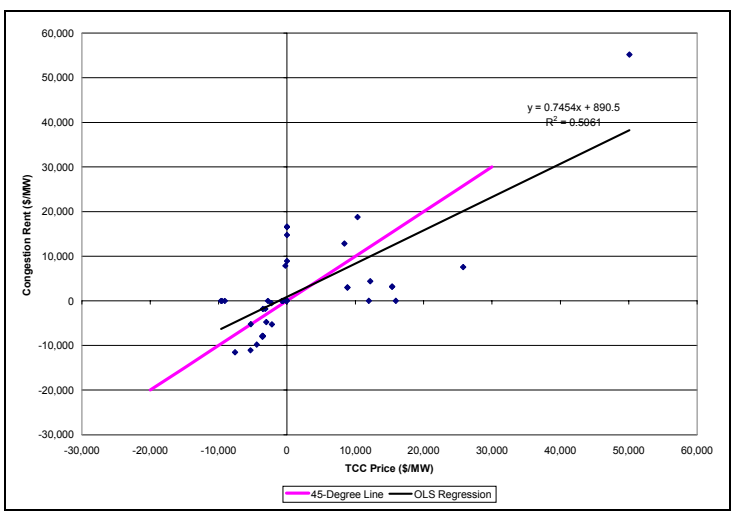

Figure 38. TCC Price Paid and Congestion Rent Collected $\mathbf{9 0 \%}$ Data for Round 3 Spring 2000 Unique Award Auction)

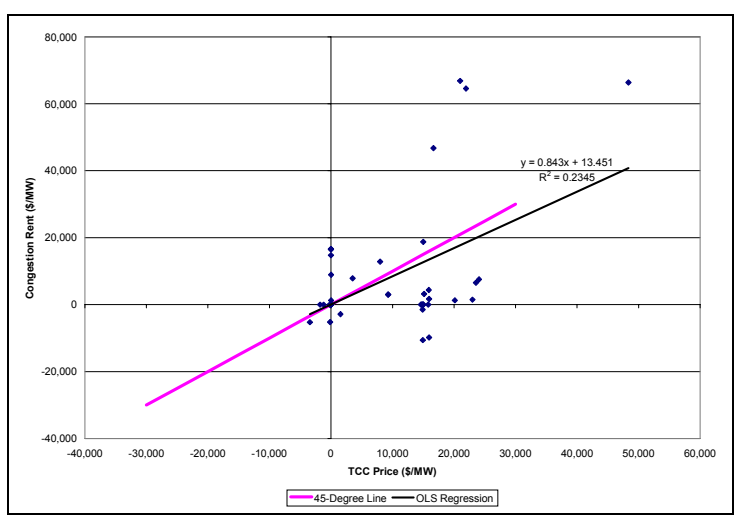

Figure 39. TCC Price Paid and Congestion Rent Collected (100\% Data for Round 4 Spring 2000 Unique Award Auction)

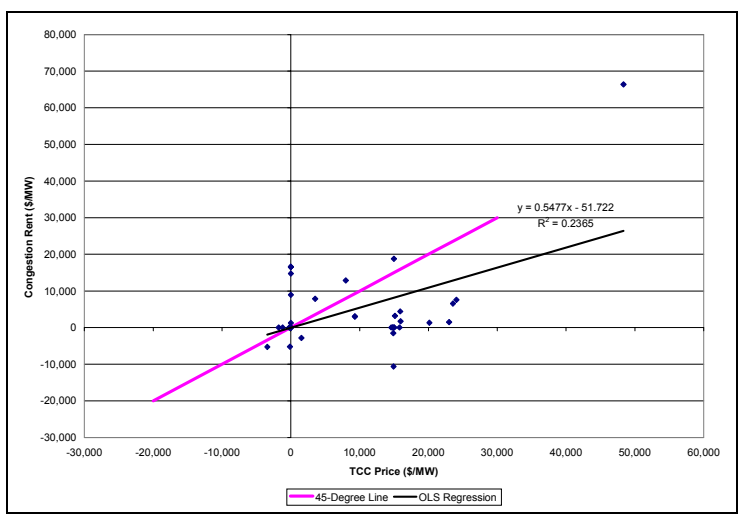

Figure 40. TCC Price Paid and Congestion Rent Collected (90\% Data for Round 4 Spring 2000 Unique Award Auction) 


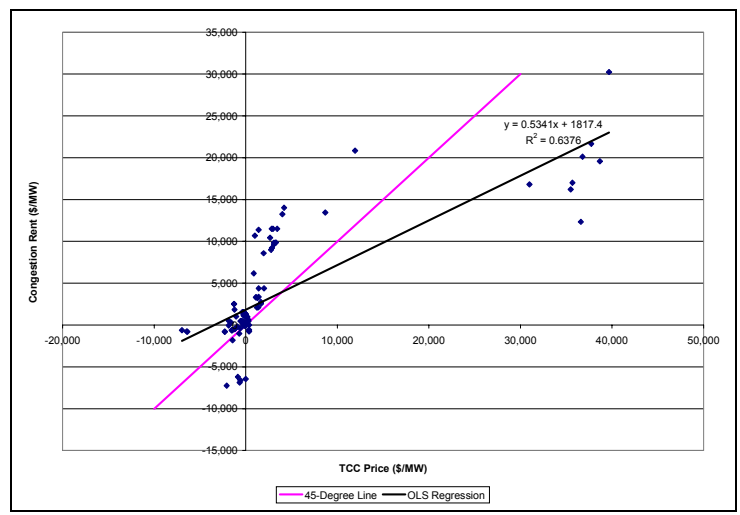

Figure 41. TCC Price Paid and Congestion Rent Collected (100\% Data for Round 1 Autumn 2000 Unique Award Auction)

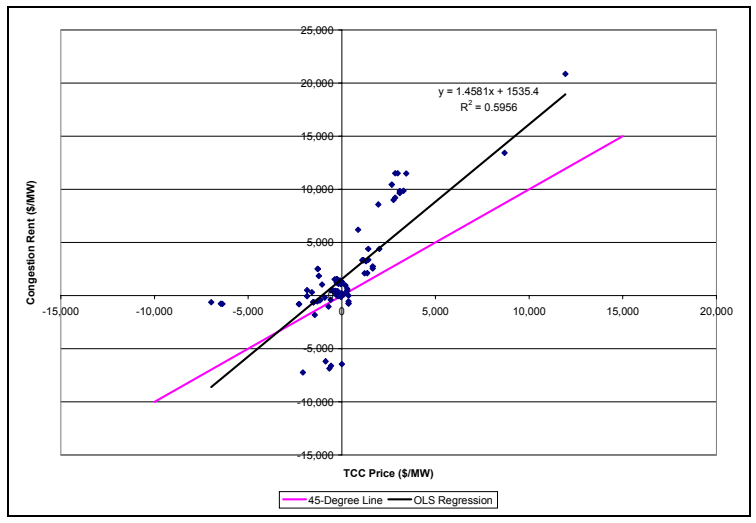

Figure 42. TCC Price Paid and Congestion Rent Collected $\mathbf{9 0 \%} \%$ Data for Round 1 Autumn 2000 Unique Award Auction)

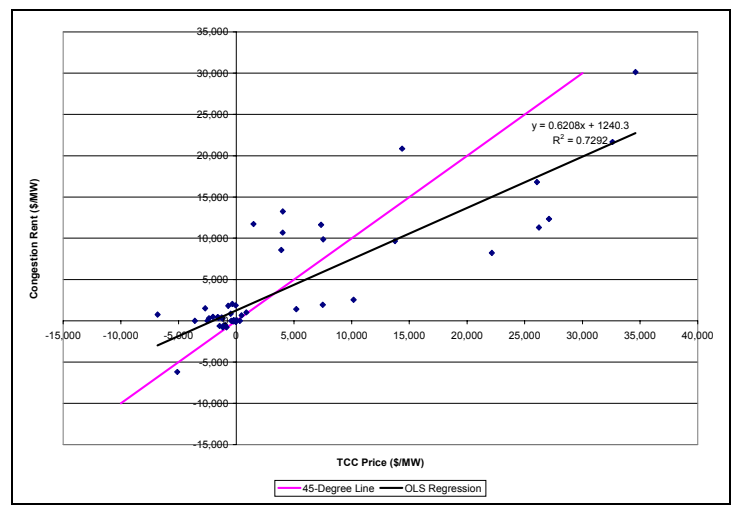

Figure 43. TCC Price Paid and Congestion Rent Collected (100\% Data for Round 2 Autumn 2000 Unique Award Auction)

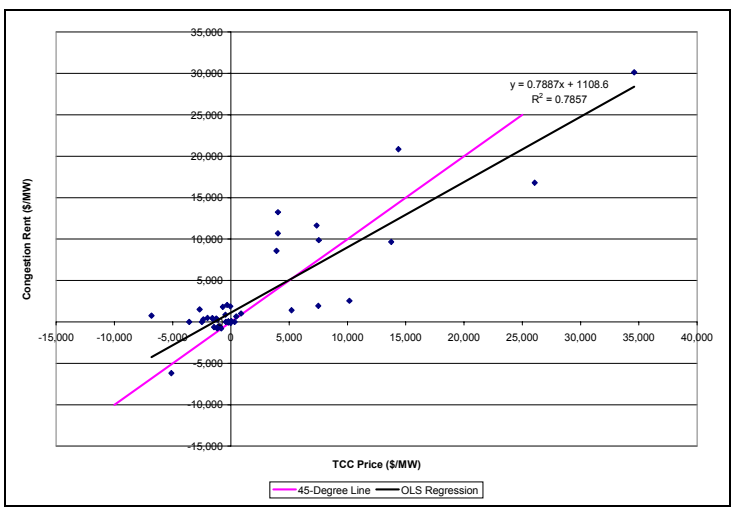

Figure 44. TCC Price Paid and Congestion Rent Collected $(90 \%$ Data for Round 2 Autumn 2000 Unique Award Auction)

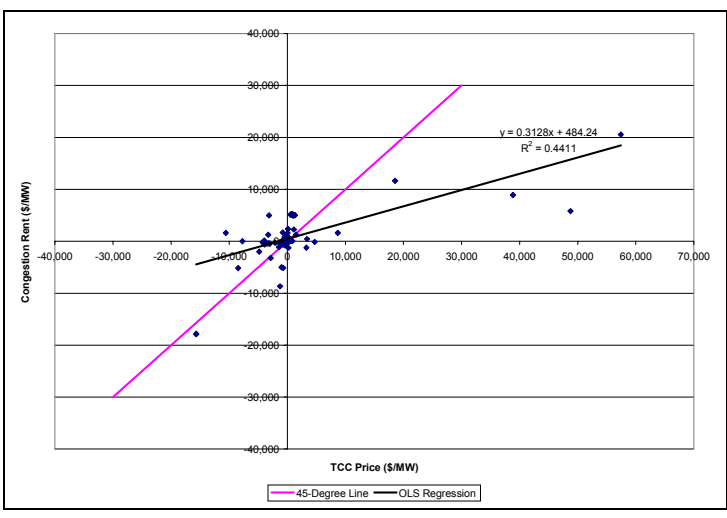

Figure 45. TCC Price Paid and Congestion Rent Collected (100\% Data for Round 1 Spring 2001 Unique Award Auction)

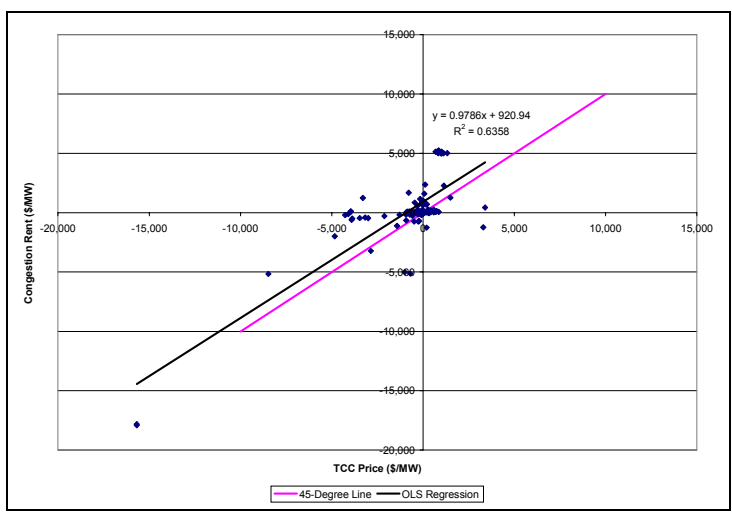

Figure 46. TCC Price Paid and Congestion Rent Collected $\mathbf{9 0 \%}$ Data for Round 1 Spring 2001 Unique Award Auction) 


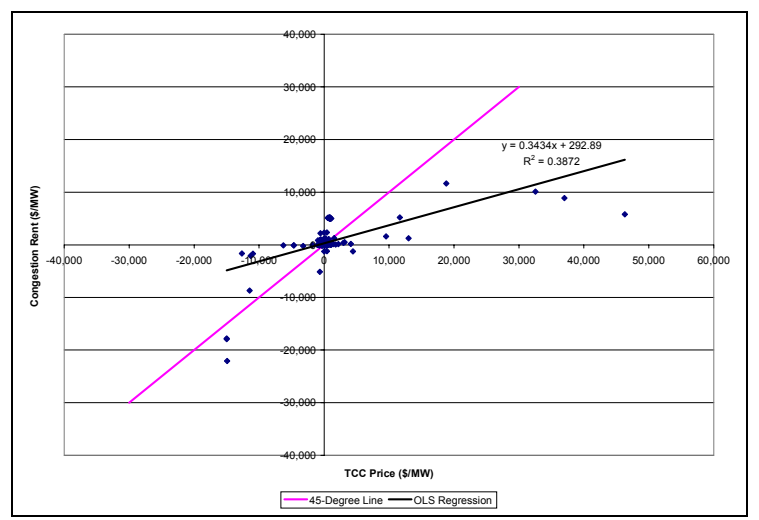

Figure 47. TCC Price Paid and Congestion Rent Collected (100\% Data for Round 2 Spring 2001 Unique Award Auction)

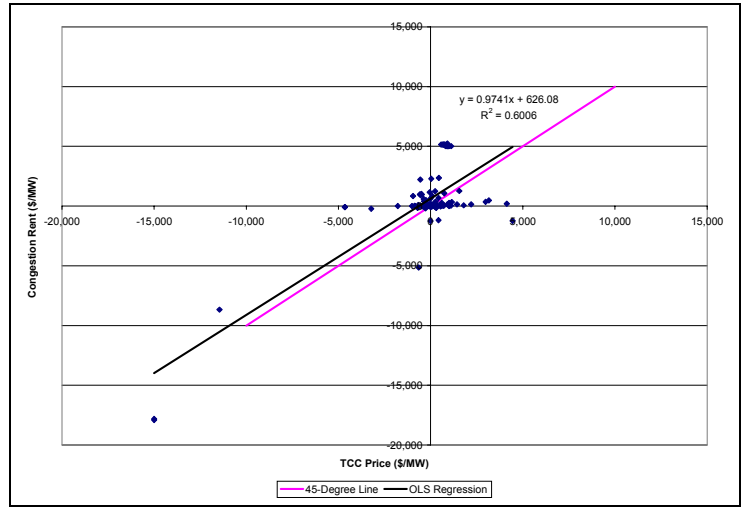

Figure 48. TCC Price Paid and Congestion Rent Collected $\mathbf{9 0} \%$ Data for Round 2 Spring 2001 Unique Award Auction)

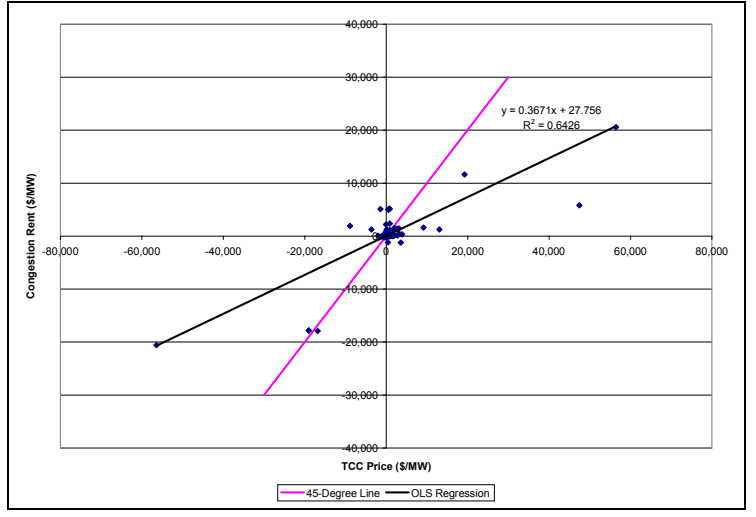

Figure 49. TCC Price Paid and Congestion Rent Collected (100\% Data for Round 3 Spring 2001 Unique Award Auction)

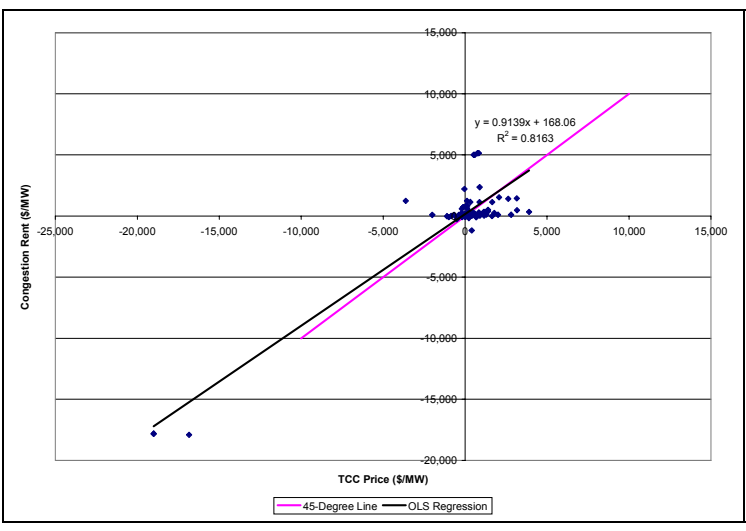

Figure 50. TCC Price Paid and Congestion Rent Collected $(90 \%$ Data for Round 3 Spring 2001 Unique Award Auction)

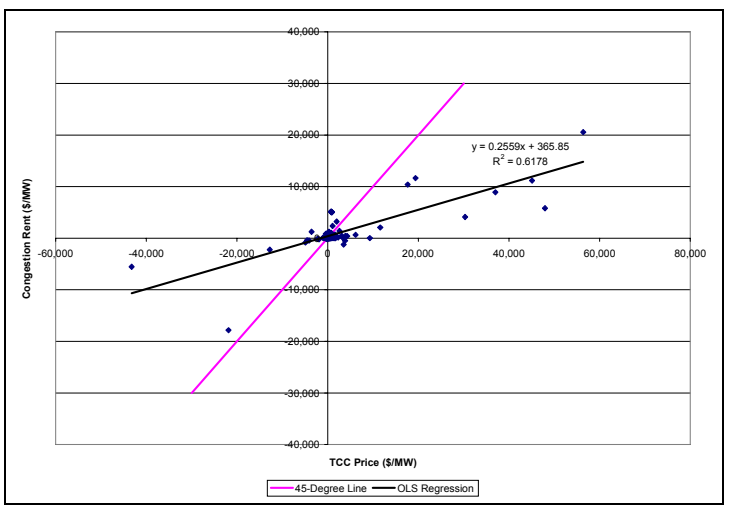

Figure 51. TCC Price Paid and Congestion Rent Collected (100\% Data for Round 4 Spring 2001 Unique Award Auction)

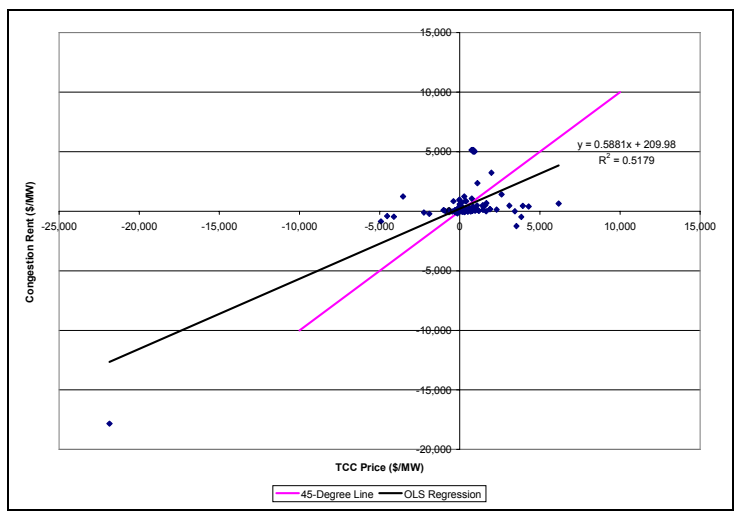

Figure 52. TCC Price Paid and Congestion Rent Collected $\mathbf{9 0 \%}$ Data for Round 4 Spring 2001 Unique Award Auction) 


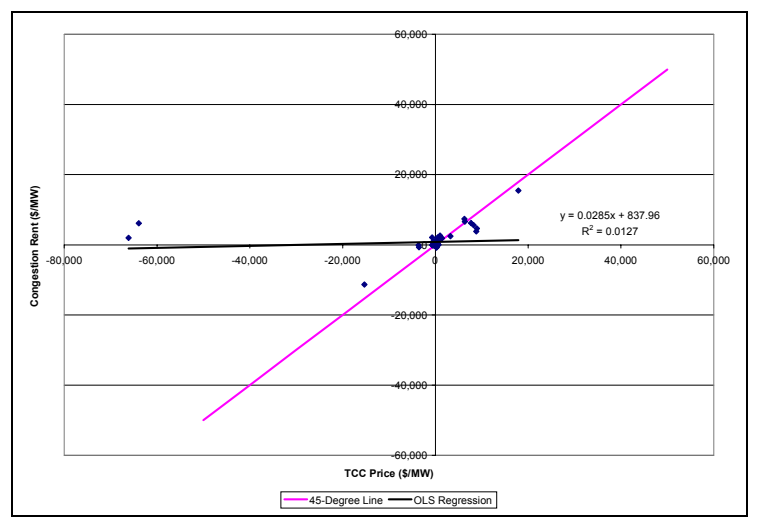

Figure 53. TCC Price Paid and Congestion Rent Collected (100\% Data for Round 3 Autumn 2001 Unique Award Auction)

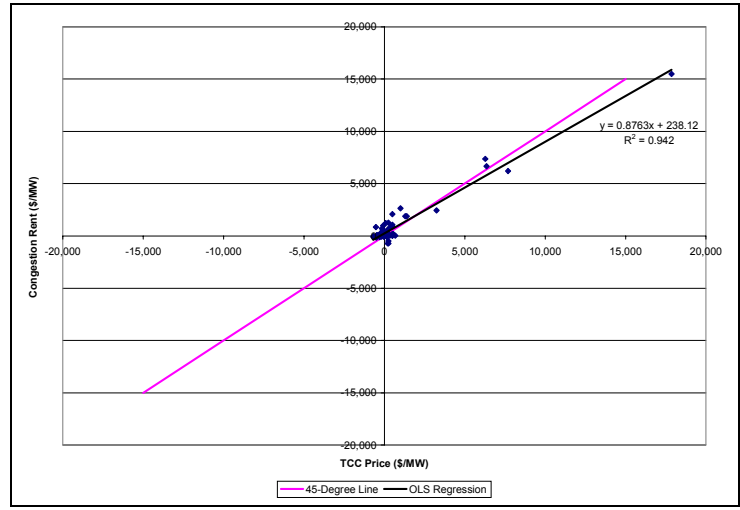

Figure 54. TCC Price Paid and Congestion Rent Collected $\mathbf{9 0} \%$ Data for Round 3 Autumn 2001 Unique Award Auction)

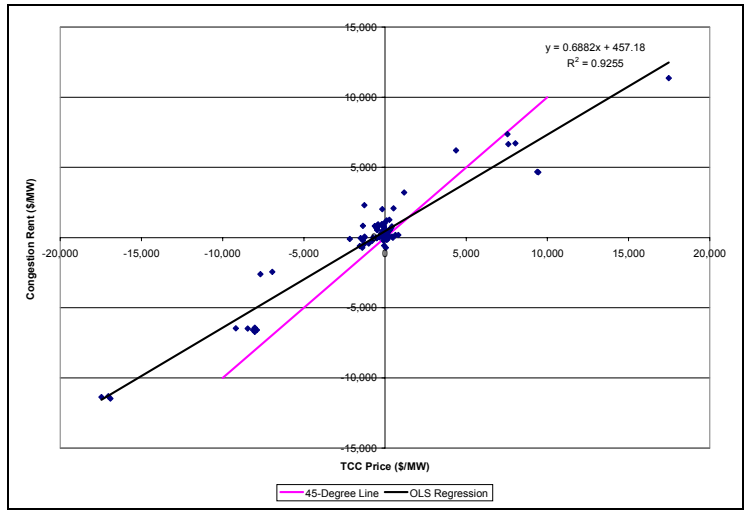

Figure 55. TCC Price Paid and Congestion Rent Collected (100\% Data for Round 4 Autumn 2001 Unique Award Auction)

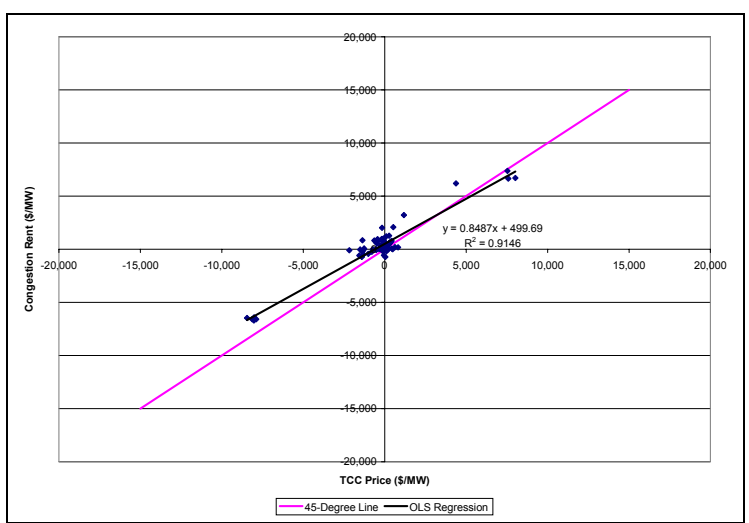

Figure 56. TCC Price Paid and Congestion Rent Collected $\mathbf{9 0 \%}$ Data for Round 4 Autumn 2001 Unique Award Auction)

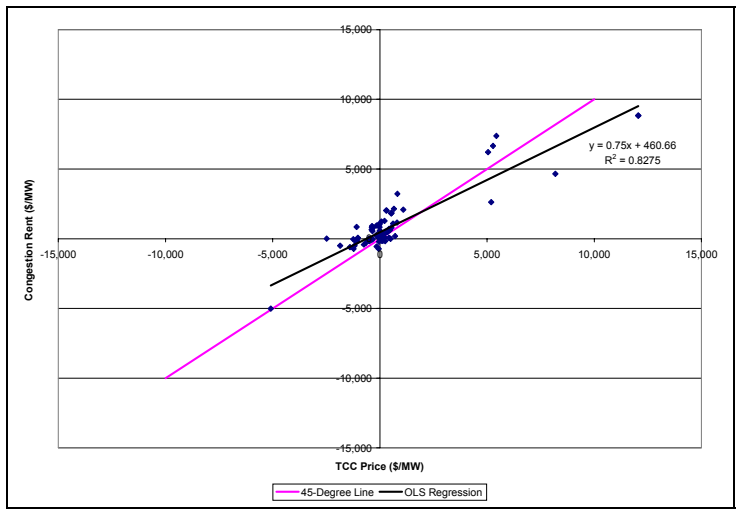

Figure 57. TCC Price Paid and Congestion Rent Collected (100\% Data for Round 5 Autumn 2001 Unique Award Auction)

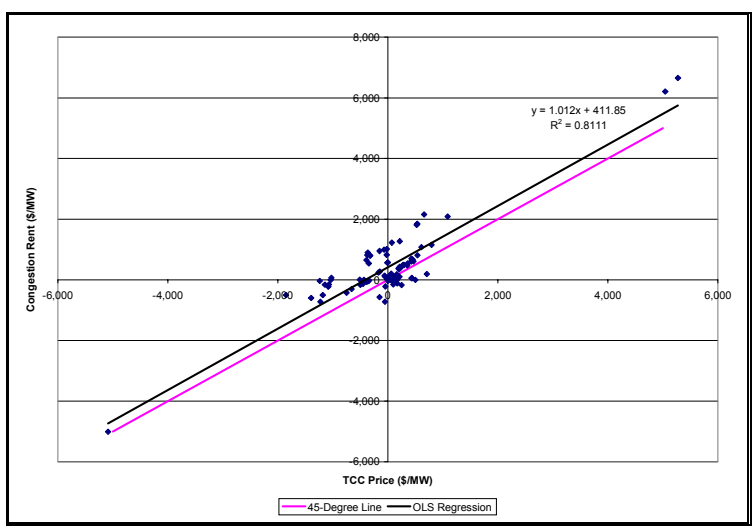

Figure 58. TCC Price Paid and Congestion Rent Collected (90\% Data for Round 5 Autumn 2001 Unique Award Auction) 


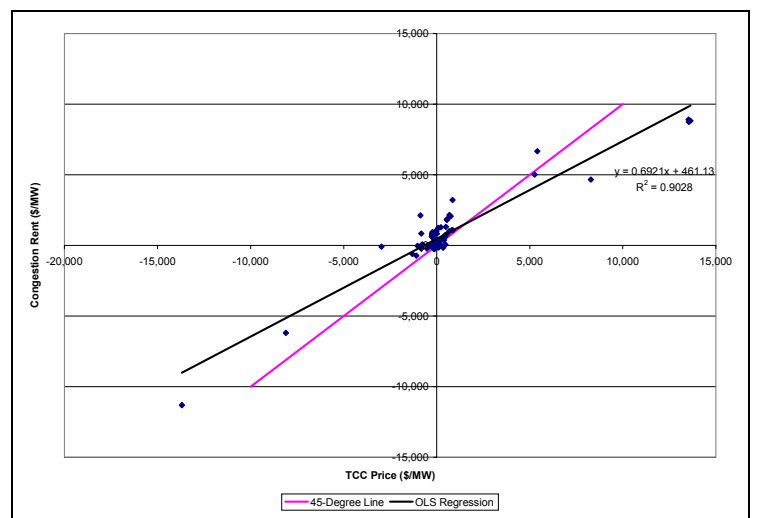

Figure 59. TCC Price Paid and Congestion Rent Collected (100\% Data for Round 6 Autumn 2001 Unique Award Auction)

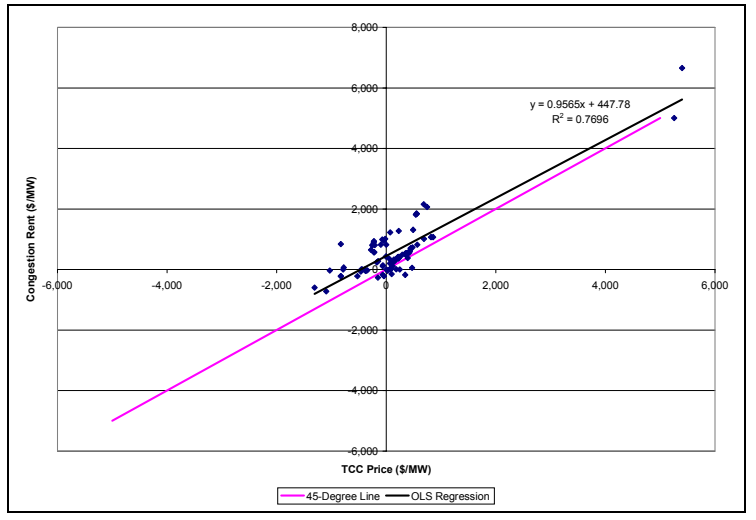

Figure 60. TCC Price Paid and Congestion Rent Collected $\mathbf{9 0} \%$ Data for Round 6 Autumn 2001 Unique Award Auction)

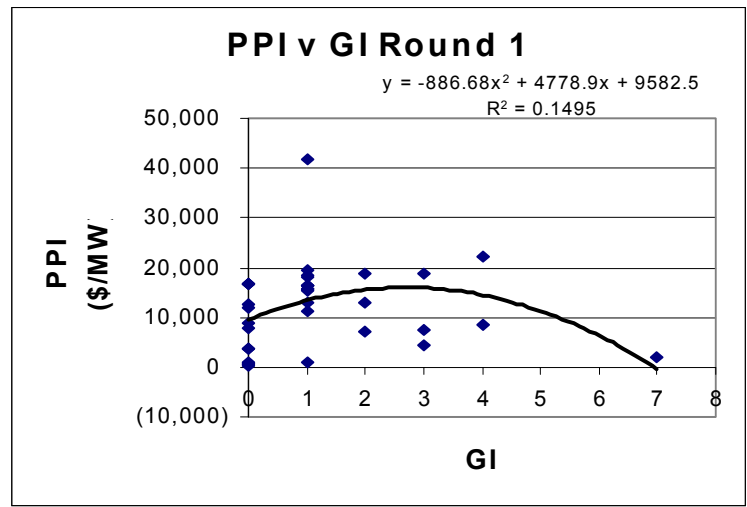

Figure 61. TCC Predictive Power Index and Geographical Indicator (100\% Data for Round 1 of Spring 2000)

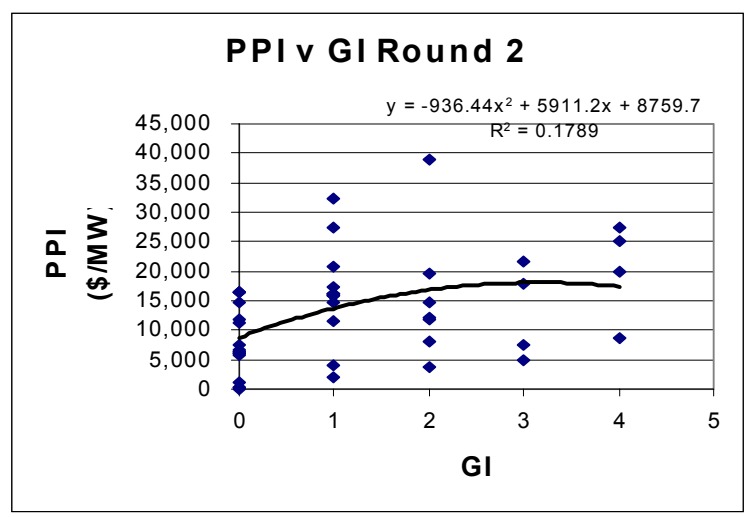

Figure 62. TCC Predictive Power Index and Geographical Indicator (100\% Data for Round 2 of Spring 2000) 


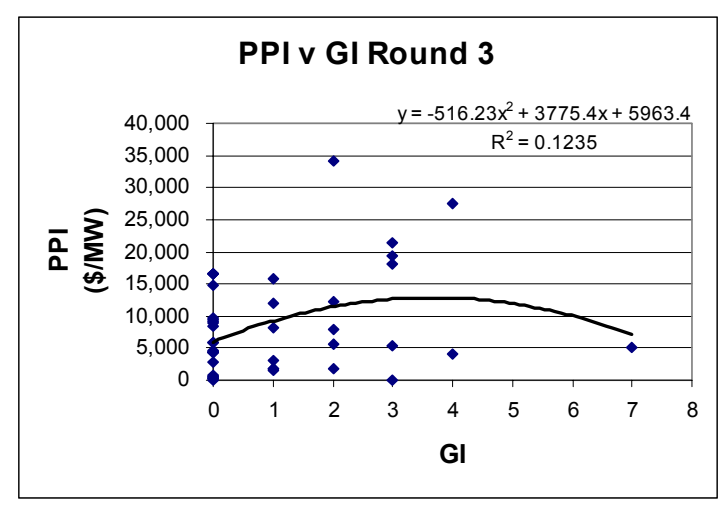

Figure 63. TCC Predictive Power Index and Geographical Indicator (100\% Data for Round 3 of Spring 2000)

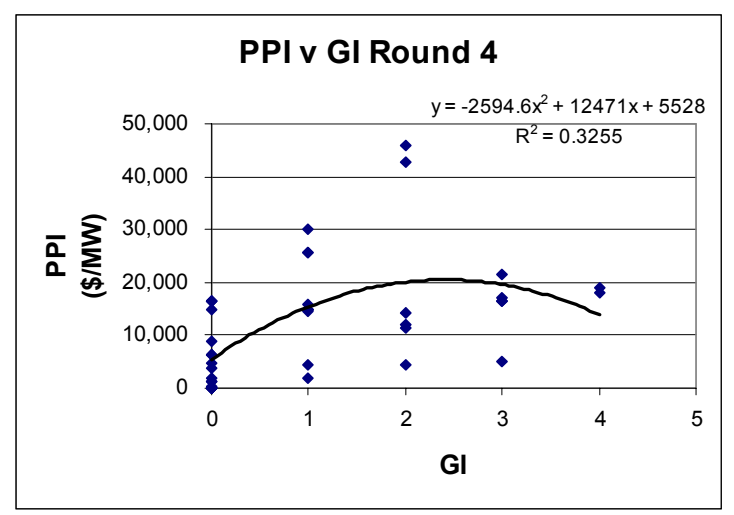

Figure 64. TCC Predictive Power Index and Geographical Indicator (100\% Data for Round 4 of Spring 2000)

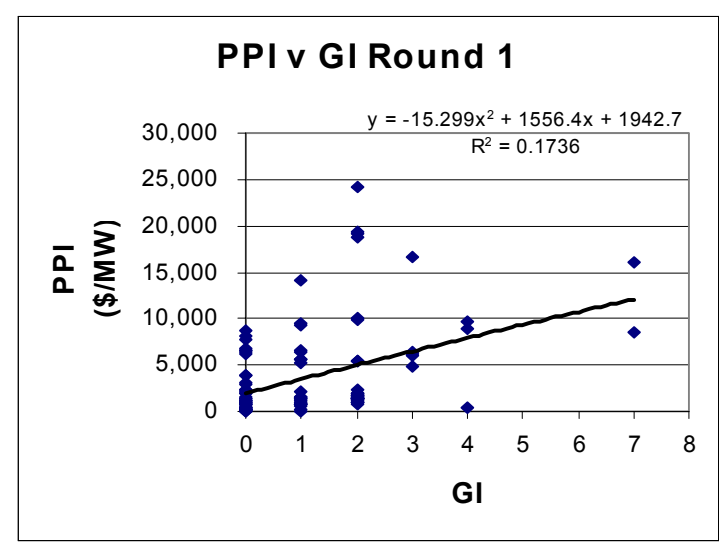

Figure 65. TCC Predictive Power Index and Geographical Indicator (100\% Data for Round 1 of Autumn 2000)

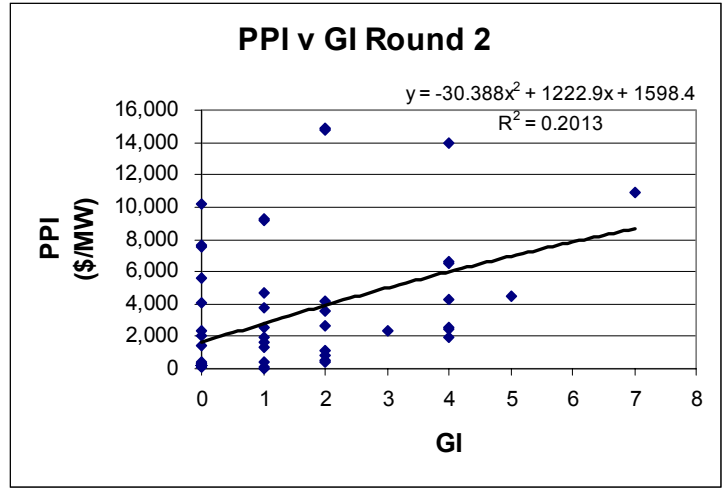

Figure 66. TCC Predictive Power Index and Geographical Indicator (100\% Data for Round 2 of Autumn 2000)

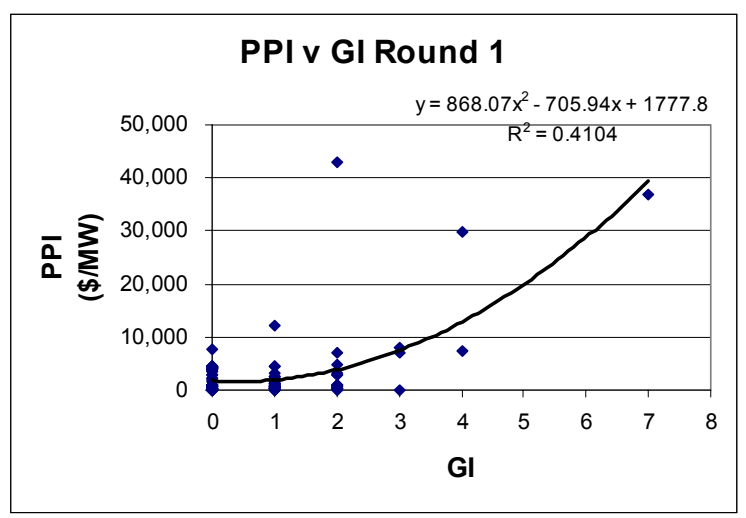

Figure 67. TCC Predictive Power Index and Geographical Indicator (100\% Data for Round 1 of Spring 2001)

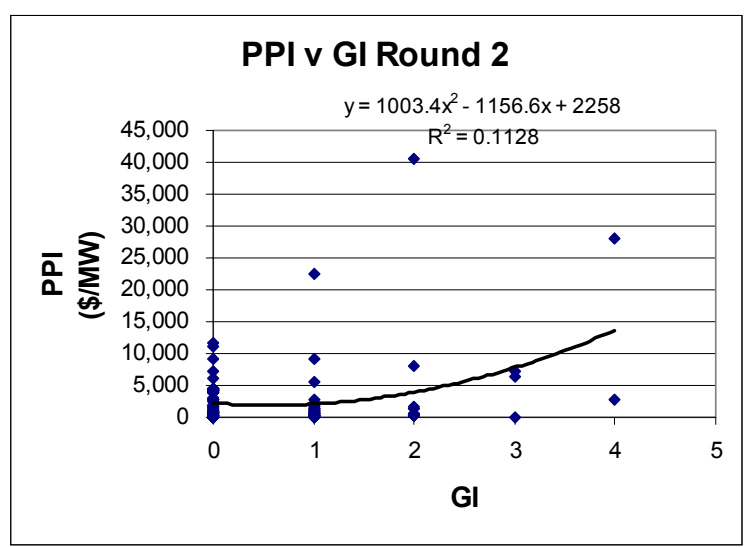

Figure 68. TCC Predictive Power Index and Geographical Indicator (100\% Data for Round 2 of Spring 2001) 


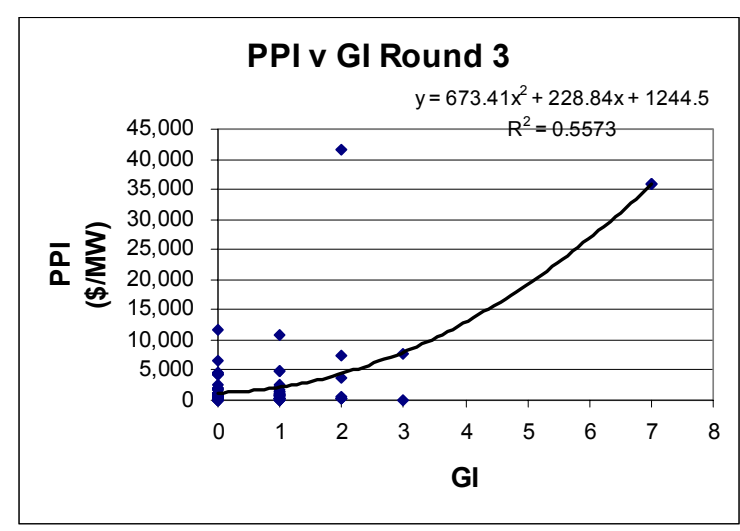

Figure 69. TCC Predictive Power Index and Geographical Indicator (100\% Data for Round 3 of Spring 2001)

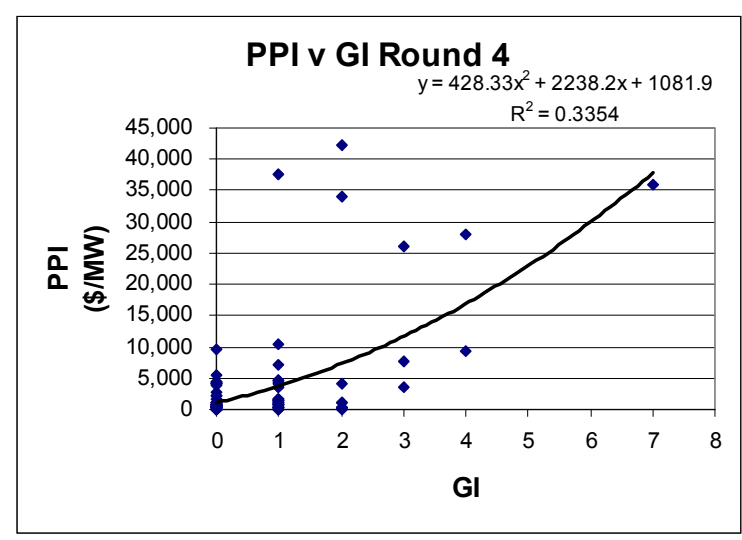

Figure 70. TCC Predictive Power Index and Geographical Indicator (100\% Data for Round 4 of Spring 2001)

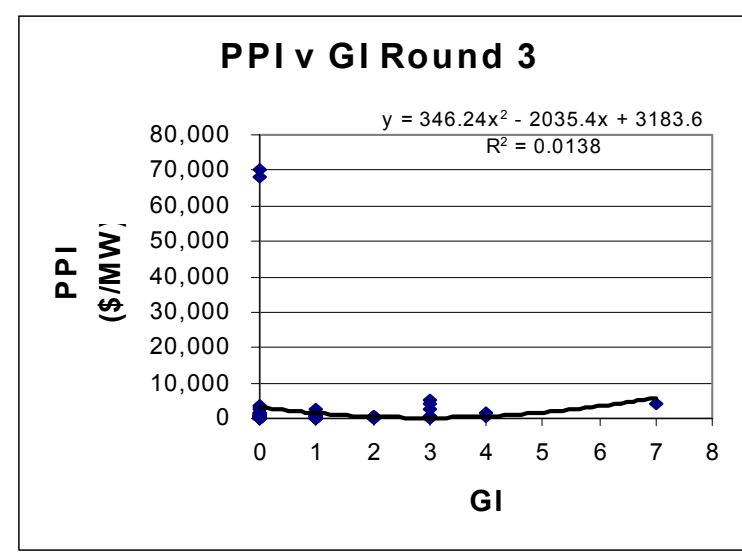

Figure 71. TCC Predictive Power Index and Geographical Indicator (100\% Data for Round 3 of Autumn 2001)

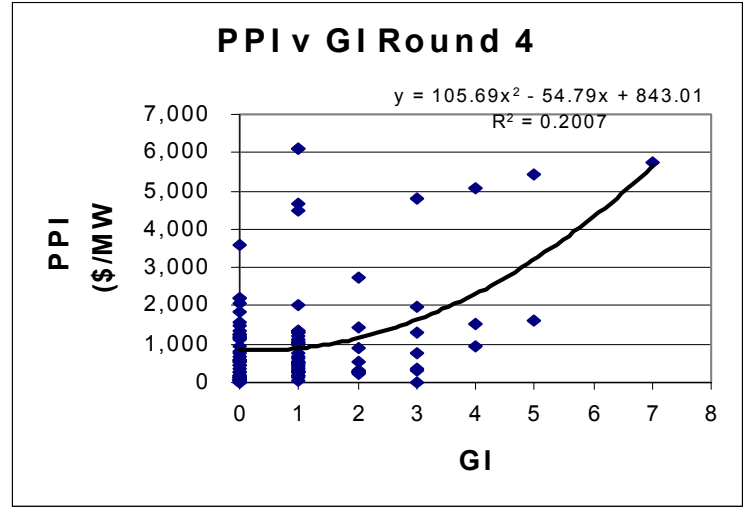

Figure 72. TCC Predictive Power Index and Geographical Indicator (100\% Data for Round 4 of Autumn 2001)

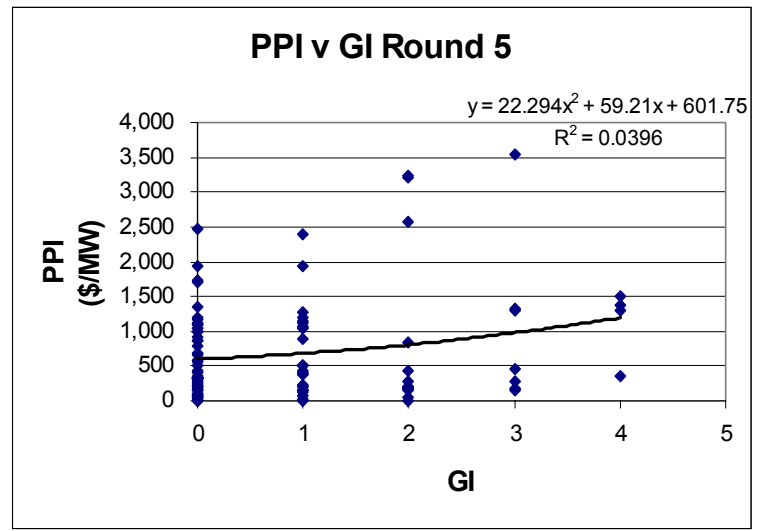

Figure 73. TCC Predictive Power Index and Geographical Indicator (100\% Data for Round 5 of Autumn 2001)

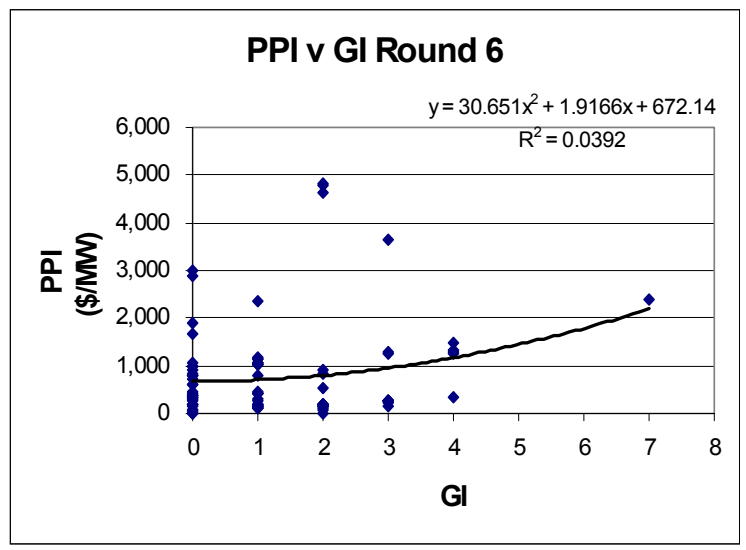

Figure 74. TCC Predictive Power Index and Geographical Indicator (100\% Data for Round 6 of Autumn 2001) 
